\title{
U.S. JOB FLOWS AND THE CHINA SHOCK
}

\author{
Brian J. Asquith \\ Sanjana Goswami \\ David Neumark \\ Antonio Rodriguez-Lopez \\ Working Paper 24080 \\ http://www.nber.org/papers/w24080 \\ NATIONAL BUREAU OF ECONOMIC RESEARCH \\ 1050 Massachusetts Avenue \\ Cambridge, MA 02138 \\ November 2017
}

We thank Penny Goldberg (our discussant), Gordon Hanson, Steve Redding, Peter Schott, and participants at the NBER Trade and Labor Markets Conference for comments and suggestions that improved this paper. The views expressed herein are those of the authors and do not necessarily reflect the views of the National Bureau of Economic Research.

NBER working papers are circulated for discussion and comment purposes. They have not been peer-reviewed or been subject to the review by the NBER Board of Directors that accompanies official NBER publications.

(C) 2017 by Brian J. Asquith, Sanjana Goswami, David Neumark, and Antonio Rodriguez-Lopez. All rights reserved. Short sections of text, not to exceed two paragraphs, may be quoted without explicit permission provided that full credit, including $(\subset)$ notice, is given to the source. 
U.S. Job Flows and the China Shock

Brian J. Asquith, Sanjana Goswami, David Neumark, and Antonio Rodriguez-Lopez

NBER Working Paper No. 24080

November 2017

JEL No. F14,F16,F6,J2,J65

\begin{abstract}
$\underline{\text { ABSTRACT }}$
International trade exposure affects job creation and destruction along the intensive margin (job flows due to expansions and contractions of firms' employment) as well as along the extensive margin (job flows due to births and deaths of firms). This paper uses 1992-2011 employment data from the universe of U.S. establishments to construct job flows at both the industry and commuting-zone levels, and then estimates the impact of the 'China shock' on each job-flow type. The China shock is accounted for by either the increase in Chinese import penetration in the U.S., or by the U.S. policy change that granted Permanent Normal Trade Relations (PNTR) status to China. We find that the China shock affects U.S. employment mainly through deaths of establishments. At the commuting-zone level, we find evidence of large job reallocation from the Chinese-competition exposed sector to the nonexposed sector, and establish that the gross employment effects of the China shock are fundamentally different from those of a more general adverse shock affecting the U.S. demand for domestic labor.
\end{abstract}

Brian J. Asquith

NBER

1050 Massachusetts Ave.

Cambridge, MA 02138

basquith86@gmail.com

Sanjana Goswami

University of California at Irvine

Irvine, CA 92697-5100

goswams1@uci.edu
David Neumark

Department of Economics

University of California at Irvine

3151 Social Science Plaza

Irvine, CA 92697

and NBER

dneumark@uci.edu

Antonio Rodriguez-Lopez

University of California at Irvine

Irvine, CA 92697-5100

antonio.rodriguez@uci.edu 
But for too many of our citizens, a different reality exists:... rusted-out factories scattered like tombstones across the landscape of our nation...

President Donald Trump, Inaugural Address, January 20, 2017

\section{Introduction}

Net employment changes conceal large changes in gross job flows. Using the universe of establishments of the U.S. from the National Establishment Time-Series (NETS) database, Figure 1 shows the ratio of three-year net employment changes (gross job creation - gross job destruction) to total gross job reallocation (gross job creation + gross job destruction) for manufacturing, nonmanufacturing, and all industries from 1992-1995 to 2009-2012. In absolute value, the averages of these ratios are only 0.16 for manufacturing, 0.17 for non-manufacturing, and 0.15 for all industries, showing a stark contrast between net employment changes and actual job turnover in the U.S. economy. Hence, to properly assess the costs and benefits of any shock that affects U.S. labor markets, it is crucial to understand not only its net employment effects but also its impact on gross job flows. ${ }^{1}$

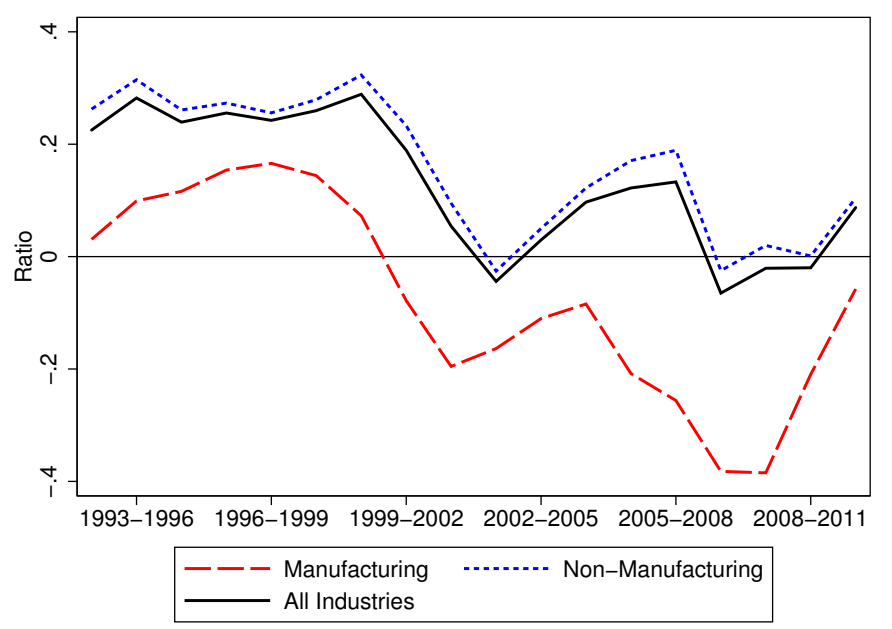

Figure 1: Ratio of U.S. net employment changes to total gross job reallocation (three-year changes)

The objective of this paper is to estimate the impact of the so-called 'China shock' on each of the components of U.S. job flows at both the industry and commuting-zone levels. We decompose gross job creation into its births and expansions components, and gross job destruction into its deaths and contractions components. Moreover, to assess the generality of our results, we perform

\footnotetext{
${ }^{1}$ For example, a shock may have near zero net employment effects but large increases in the rates of job creation and destruction. More job creation and destruction could potentially increase costs of adjustment for both firms and workers, but this would be missed by an analysis based on net employment changes.
} 
our analysis using the two most influential measures of the China shock in the recent literature: the increase in Chinese import penetration in the U.S. (from Autor, Dorn, and Hanson, 2013), and the U.S. trade policy change that granted Permanent Normal Trade Relations (PNTR) status to China (from Pierce and Schott, 2016-PS hereafter). To guide our empirical exercise we build on the comprehensive work of Acemoglu, Autor, Dorn, Hanson, and Price (2016) - AADHP hereafterwho in addition to a local labor markets analysis of the China shock on net employment changes as in Autor, Dorn, and Hanson (2013), perform an industry-level analysis that considers manufacturing and non-manufacturing industries, as well as upstream and downstream linkages across industries.

In addition to providing a more complete picture of U.S. employment dynamics after the China trade shock, our focus on job flows is within the scope of modern models of trade with heterogeneous firms. Indeed, the seminal models of Bernard, Eaton, Jensen, and Kortum (2003) and Melitz (2003) have clear-cut implications for the effects of trade liberalization on gross job creation and destruction. For example, in their Ricardian model simulation of a 5 percent decline in trade barriers, Bernard, Eaton, Jensen, and Kortum (2003) obtain an increase of 1.5 percent in the rate of gross job creation (from plants that expand) and an increase of 2.8 percent in the rate of job destruction (from plants that contract or die), for a net employment decline of 1.3 percent. Bernard, Redding, and Schott (2007) tackle the job turnover implications of a Heckscher-Ohlin augmented version of the Melitz model. After trade liberalization, the standard Melitz model predicts gross job creation from expanding exporting firms and new entrants, and gross job destruction from the death and contraction of less productive firms. In their version, Bernard, Redding, and Schott (2007) obtain that the net employment effect is positive in the industries in which a country has comparative advantage, and is negative otherwise.

Using either import exposure or PNTR-status exposure as the measure of the China shock, our empirical analysis shows that U.S. net job destruction due to the China shock is mainly driven by an increase in the rate of job destruction due to deaths of establishments. At the industry level, this result appears not only for the direct effect of the China shock, but also for its upstream and downstream effects (the effects that flow from buying industries to a selling industry, and vice versa). At the commuting-zone level, the deaths result appears for the impact of local exposure to the China shock on the Chinese-competition exposed sector. Across specifications, the estimated share of deaths in total Chinese-induced job reallocation ranges between 55 and 98 percent.

This paper also finds novel evidence of Chinese-induced job reallocation effects from the exposed sector to the nonexposed sector at the commuting-zone level. The nonexposed sector is indirectly affected by the China shock through job reallocation effects and aggregate demand effects. Given 
that these indirect channels have opposite effects on the nonexposed sector's employment, it is not surprising that previous studies have not found evidence of them when looking at net employment changes (they cancel each other out). This paper is not only able to find statistically significant evidence of net job reallocation effects, but by focusing on all the job flows components, it is also able to capture evidence of these counteracting indirect effects.

Highlighting the benefits of looking at job flows, we find that the large and positive net job reallocation from the exposed sector to the nonexposed nontradable sector happens in spite of a large increase in the latter sector's rate of job destruction by deaths (evidence of aggregate demand effects), which is dominated by an even larger increase in the rate of job creation by births (evidence of job reallocation effects). When using import exposure as the measure of the China shock, the net job creation in the nonexposed sector is as large as the net job destruction in the exposed sector, resulting in an almost neutral net effect of the China shock.

Our local labor markets analysis also allows us to establish the uniqueness of the gross employment effects of the China shock. Although previous contributions have noted the negative net employments effects of Chinese exposure in the U.S., they cannot establish whether the China-shock job turnover effects are similar to the effects of a generic adverse shock affecting the U.S. demand for labor. Using a general Bartik shock variable at the commuting-zone level, which accounts for national changes in labor demand while taking into account regional specialization patterns, we show that the effects of the China shock on gross job flows are fundamentally different from the effects of a generic adverse labor demand shock. In particular, while an adverse Bartik shock causes net job destruction mainly through a reduction in the rates of job creation by births and expansions, the China-shock net job destruction is mainly driven by the increase in deaths. Moreover, the adverse Bartik shock implies a decline in the rate of job destruction by deaths (the opposite to the China shock), which helps counteract the amount of job destruction driven by the decline in births and expansions.

This paper highlights the important role that deaths of establishments play in U.S. net job destruction as a consequence of the China shock. This result is useful to better gauge the associated benefits and costs of increased trade with China. On the one hand, if dying firms are unproductive or obsolete, the China shock may simply be accelerating the process of creative destruction, which may lead to productivity increases and is a source of benefits (see, for example, Davis, Haltiwanger, and Schuh, 1996). ${ }^{2}$ On the other hand, a net employment decline due to an increase in job destruction by deaths of establishments is likely to be more costly than a decline due to a reduction in the rate

\footnotetext{
${ }^{2}$ These benefits would be reduced if the China shock also negatively affects the rate of births. A couple of our specifications find a significant negative relationship between births and Chinese exposure.
} 
of expansions or births. Along these lines, Klein, Schuh, and Triest (2003) refer to the destruction of human capital, and search and relocation costs associated with higher rates of job destruction, as opposed to less pervasive effects of a reduction in the rate of job creation.

Moreover, this paper's findings on job reallocation from the Chinese-competition exposed sector to the nonexposed sector shed light on what happens in general equilibrium after a trade shock. Typically, general-equilibrium models of trade in the heterogenous-firm tradition include two sectors, one tradable and one nontradable. Due to usual quasi-linearity assumptions, a trade shock causes interesting dynamics - entry, exit, expansions, and contractions of firms - only in the tradable sector, and whatever labor is released from that sector is immediately absorbed by the residual nontradable sector. ${ }^{3}$ In contrast, this paper documents that interesting dynamics also happen in the nontradable sector. Our findings for the China shock - the exposed sector releases labor (mostly) through deaths, while the nonexposed sector absorbs released labor (mostly) through birthsprovide insights that can help guide future theoretical work on how to study the trade-induced job-reallocation mechanism across sectors.

This paper is organized as follows. Section 2 describes the NETS data, and section 3 provides a brief overview of the evolution of job flows. Section 4 describes the construction of the two measures of the China shock. Sections 5 and 6 present our empirical analysis for the impact of Chinese exposure on U.S. job flows, starting with the industry-level analysis and then moving to the local labor markets approach. Lastly, section 7 concludes.

\section{Job Flows Data}

This paper constructs job flows from the National Establishment Time Series (NETS) database, which reports yearly data on employment, sales, industry, location, year of entry, and year of exit, for the universe of establishments in the U.S. from 1992 to $2012 .^{4}$

As described by Neumark, Zhang, and Wall (2007) and Neumark, Wall, and Zhang (2011), who

\footnotetext{
${ }^{3}$ Although there are some exceptions (see, e.g., Groizard, Ranjan, and Rodriguez-Lopez, 2014 and the references cited therein), most general-equilibrium trade models have full employment.

${ }^{4}$ The NETS data are collected by Walls and Associates in conjunction with Dun and Bradstreet (D\&B) to convert D\&B's archival establishment data into a panel dataset at the establishment level. D\&B have a rich information set on establishments through their issuance of DUNS Numbers, which are unique, 9-digit identification numbers assigned to each physical location of a business and is intended to follow an establishment even in the event of a relocation, acquisition, or merger. Businesses usually request a DUNS Number because it is used in credit reporting, and is required to bid on government contracts (see https://www.sba.gov/contracting/getting-started-contractor/get-d-un-s-number). Every January, Wall and Associates take a "snapshot" of the Duns Marketing Information File (DMI), which is a database maintained by D\&B of the companies registered with them. These snapshots help determine which establishments are still active as of January of a given year. Active establishments can then be linked with other D\&B datasets, like their Credit Rating file. Taken altogether, Walls and Associates is able to create a curated panel dataset of establishments drawn from business-self reporting and cross-checked by both Walls and Associates and D\&B for accuracy.
} 
provide an exhaustive assessment of the NETS database, the NETS data reports higher employment levels than the BLS's Quarterly Census of Employment and Wages (QCEW). They attribute the difference to better coverage in the NETS of small establishments, as well as to the fact that the BLS data excludes self-employed workers and proprietors. Comparing the NETS data against the Current Employment Statistics (CES) database of the BLS, Neumark, Wall, and Zhang (2011) find that their correlation at the county-by-industry level is 0.99 . Also, focusing on biotech companies, they show that NETS is able to detect 88 percent of new companies within a year. Their assessment also reports some employment stickiness in the NETS data from year to year, and argue that threeperiod differences are sufficient to avoid most of this problem. By calculating job flows over seven-, eight-, and twelve-year periods, we are confident that our empirical analysis largely avoids the NETS stickiness problem.

Haltiwanger, Jarmin, and Miranda (2013) compare the Longitudinal Business Database (LBD) of the Census Bureau against the NETS database and report that while the LBD contains about 7 million establishments in a typical year, the NETS contains about 14.7 million establishments in a typical year. They attribute the difference to the inclusion of nonemployer businesses in the NETS, while the LBD includes establishments if they have at least one employee. To avoid nonemployer businesses, we restrict our NETS data to establishments that had two or more employees in at least one year in our sample.

AADHP use employment data from the County Business Patterns (CBP) of the Census Bureau. After carefully following AADHP's industry codes, we create a version of the NETS database that matches their industry classification. There are 392 industries at the four-digit Standard Industry Classification (SIC) level, and 87 non-manufacturing industries. At the industry level, the correlation between employment levels of the CBP database and our NETS database is 0.93, while at the commuting-zone level the correlation is 0.99. On average, our NETS data reports about 24 percent more employment for all industries, and 21 percent more employment for manufacturing industries.

\section{A Brief Description of U.S. Job Flows}

We calculate job flows from our NETS dataset as follows. Let $L_{i j t}$ denote total employment in commuting zone $i$, in industry $j$, at year $t$. Hence, for any period $\tau$ starting in year $t_{\tau, \text { start }}$ and ending in year $t_{\tau, \text { end }}$, it always holds that

$$
L_{i j t_{\tau, \text { end }}}-L_{i j t_{\tau, \text { start }}} \equiv \underbrace{\left(B_{i j \tau}-D_{i j \tau}\right)}_{\text {Extensive margin }}+\underbrace{\left(E_{i j \tau}-C_{i j \tau}\right)}_{\text {Intensive margin }},
$$


where $L_{i j t_{\tau, \text { end }}}-L_{i j t_{\tau, \text { start }}}$ is the net employment change during period $\tau, B_{i j \tau}$ is the employment change due to births of establishments, $D_{i j \tau}$ is the employment change due to deaths of establishments, $E_{i j \tau}$ is the employment change due to expansions of establishments, and $C_{i j \tau}$ is the employment change due to contractions of establishments. After obtaining the industry-commuting zone level data, we can aggregate at the industry level, or at the commuting zone level. The previous identity ignores the relocation margin of employment, i.e., move-ins and move-outs of establishments across commuting zones. However, as shown by Neumark, Zhang, and Wall (2007) using the NETS data, the relocation margin is largely insignificant, so we exclude it from the computations to sharpen the focus on the four job-flow drivers described above. ${ }^{5}$

Figure 2 shows four metrics for the three-year changes in job flows across all industries from 1992 to 2012. The first metric shows job creation due to births and expansions (Figure 2a), the second shows the average share of job creation due each to births and expansions (Figure 2b), the third shows job destruction due to deaths and contractions (Figure 2c), and the fourth and last shows the average share of job destruction due each to deaths and contractions (Figure 2d). Unsurprisingly, Figure 2a shows a peak for births toward the end of the 1990s, and Figure 2c shows two peaks for deaths around 2001-2004 and 2008-2011. Figures 2b and 2d show that births and deaths dominate the job creation and destruction processes, respectively.

Table A.1 in the online Appendix gives more detail on these job flows. ${ }^{6}$ Total jobs grew consistently over the 1990s, but job growth since 2000 was more anemic, with net job destruction occurring over 2001-2004 and then again in 2006-2009, 2007-2010, and 2008-2011, coinciding with the bursting of the Dotcom Bubble and the Great Recession. Prior to 2001-2004, births were far and away the largest single factor in job flows, but since then, deaths took over as the most important source of job reallocation. Figure 3 illustrates the patterns in Table A.1 by showing the evolutions of the net extensive margin of employment (Births - Deaths), the intensive margin of employment (Expansions - Contractions), and overall net job creation. Note that the intensive margin is a source of job creation for the U.S. economy during the entire period (except briefly over 2001-2004), but the extensive margin is the main driver of overall net effects.

Breaking out the job flows by industry groupings, Figure 4a shows net employment changes at the intensive margin, the extensive margin, and overall in the manufacturing sector. The net intensive margin of employment was positive until 1998-2001, and since then it was negative most of the time (the exceptions were 2002-2005, 2003-2006, and 2009-2012). The extensive margin of

\footnotetext{
${ }^{5}$ The NETS dataset reports the first and last year an establishment was in business, irrespective of whether it relocated. We use these variables to report when a firm was born and died, so that a business relocation cannot be confused with a birth or death.

${ }^{6}$ The Appendix is available at http://www.socsci.uci.edu/ jantonio/Papers/jobflows_chinashock_app.pdf.
} 


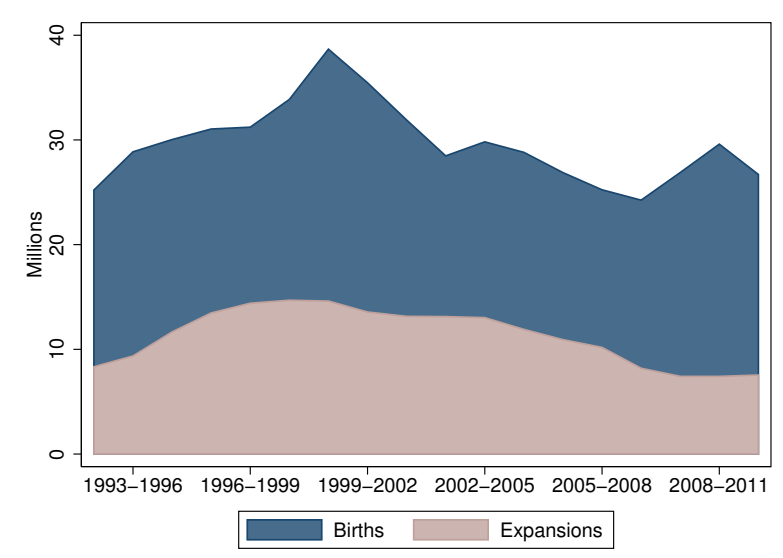

(a) Job creation decomposition

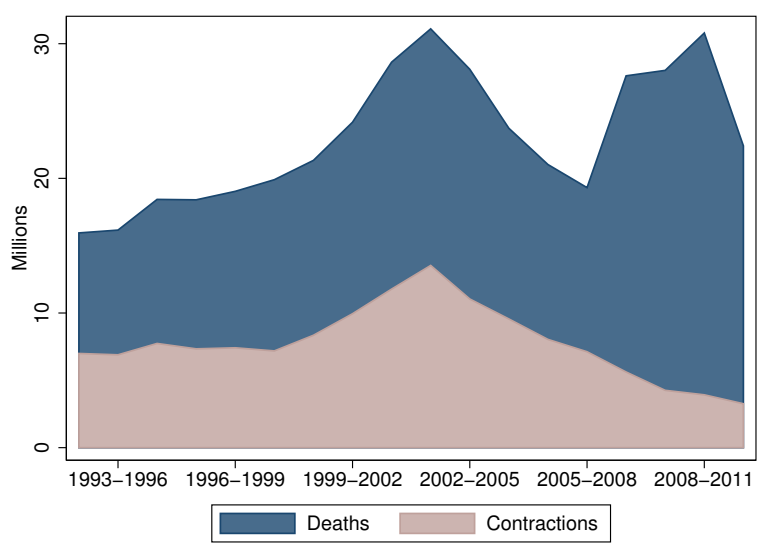

(c) Job destruction decomposition

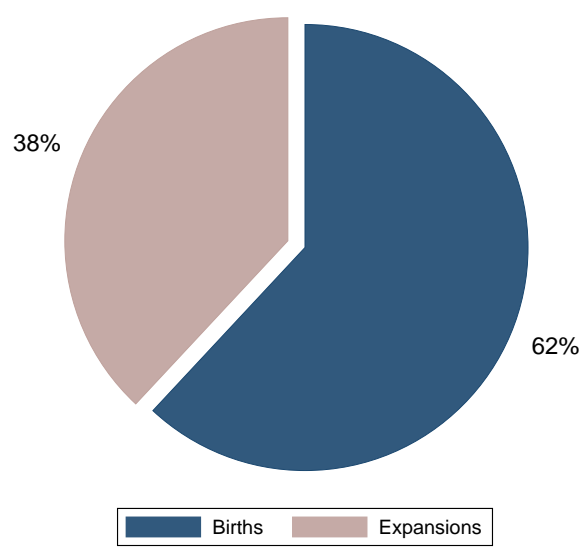

(b) Job creation shares (average)

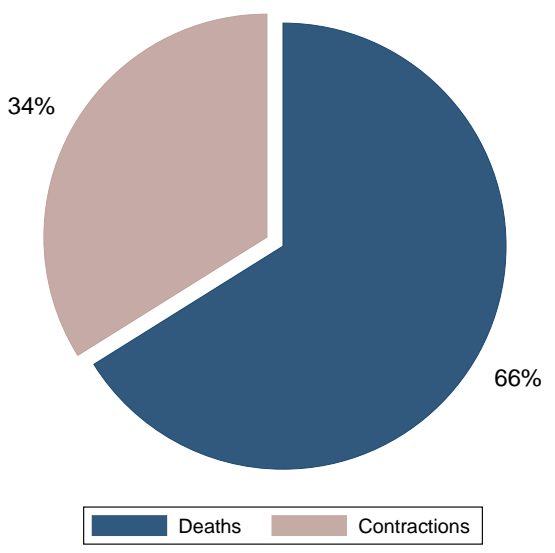

(d) Job destruction shares (average)

Figure 2: Employment creation and destruction in all industries (three-year windows)

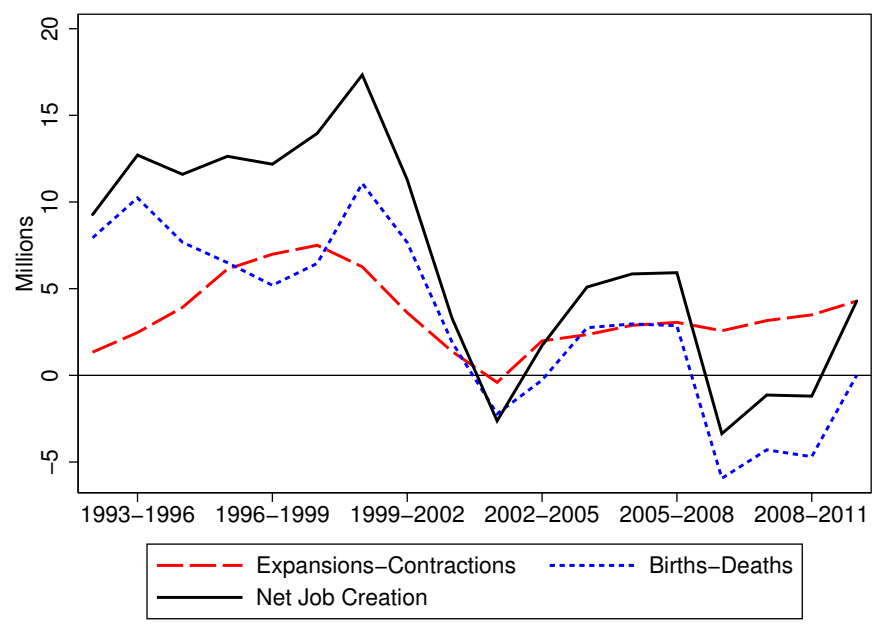

Figure 3: Net employment changes in all industries 


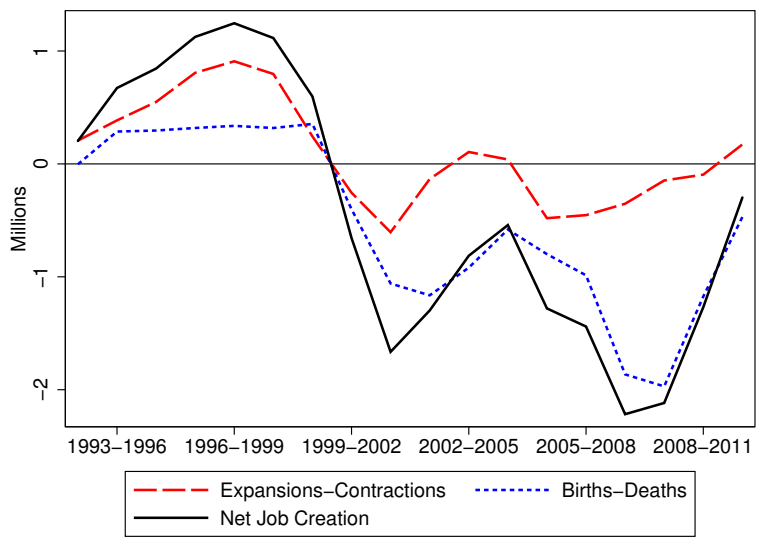

(a) Manufacturing industry

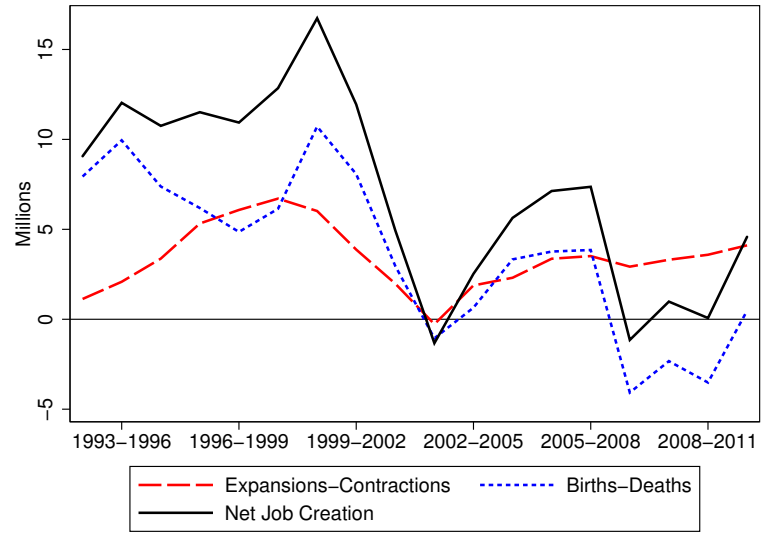

(b) Non-manufacturing industry

Figure 4: Net employment changes by industry

employment remained negative since 1999-2002, reaching an all-time low in 2007-2010. In contrast to the overall economy, and driven strongly by establishments' deaths, net job creation in manufacturing never returned to being positive after the 2001 recession-manufacturing net job losses progressed steadily in the post-2000 period, reaching their nadir during the Great Recession. For the non-manufacturing sector, which on average accounts for 86 percent of total employment per year, Figure $4 \mathrm{~b}$ is of course very similar to Figure $3 .^{7}$

The last stylized fact we present is that the relative importance of the extensive margin processes grew sharply after the Great Recession. For both the manufacturing and non-manufacturing sectors, Figures $5 \mathrm{a}$ and $5 \mathrm{~b}$ show a strong increase in the death share in job destruction starting from 2005-2008. As well, the birth share in job creation also experienced a steady increase starting from 2005-2008. Hence, in the post-Great Recession period, the extensive margin of employment accounted for a much larger share in total job reallocation than it did previously, speaking again to the importance of using the NETS dataset to tease out changes in the intensive and extensive margins.

\footnotetext{
${ }^{7}$ Figures A.1 and A.2 in the Appendix show the composition and evolution of gross job creation and gross job destruction in the manufacturing and non-manufacturing sectors. For the manufacturing sector we observe a steady decline in gross job creation since the early 2000s, leading to an all-time low in 2007-2010, and then followed by a sharp increase in births of new establishments post-2010. Unlike in the overall economy, births and expansions in manufacturing had on average an almost equal share in job creation. Job destruction in manufacturing started a sharp increase in 1996-1999, reaching its peak in 2000-2003. This was followed by a sharp decline, driven mostly by decreasing contractions of establishments. In manufacturing, 59 percent of gross job destruction is accounted for by deaths of establishments. For the non-manufacturing sector, gross job creation and destruction follow similar trends to those observed for the overall economy in Figure 2.
} 


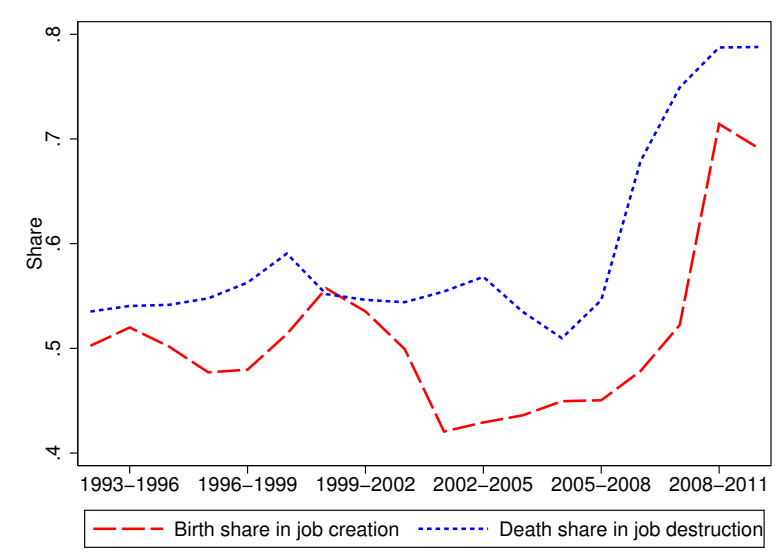

(a) Manufacturing industry

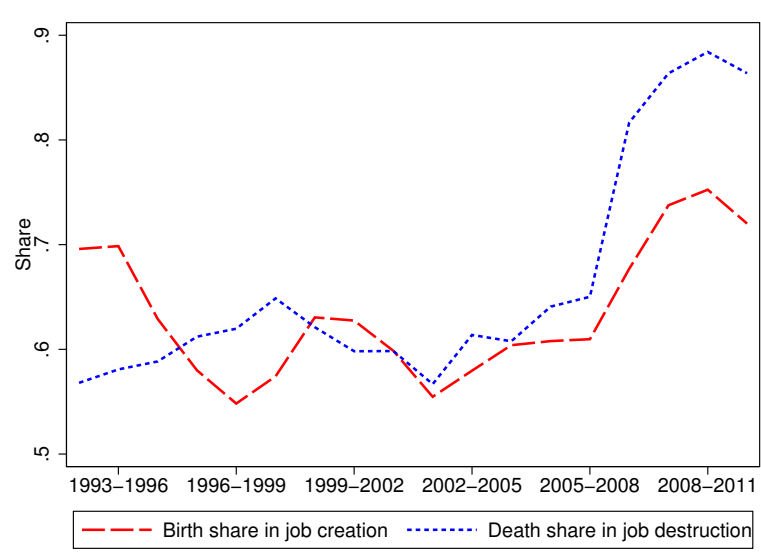

(b) Non-manufacturing industry

Figure 5: Share of births and deaths in job creation and destruction

\section{Measures of the China Shock}

To assess the generality of our results, we use the two most influential measures that attempt to capture the China shock in the United States: (i) the measure of Autor, Dorn, and Hanson (2013) and AADHP, which captures the change in Chinese import penetration, and (ii) the measure of Pierce and Schott (2016), which captures the U.S. trade policy change of granting PNTR status to China.

This section describes the construction of the two measures for the 392 manufacturing industries in our dataset. From this section's measures of the China shock for the manufacturing industries, we construct upstream and downstream measures of the China shock for all manufacturing and non-manufacturing industries (in section 5.2), and measures of commuting-zone level exposure to the China shock (in section 6).

\subsection{Chinese Import Exposure}

Closely following AADHP, our empirical analysis focuses on three subperiods: 1992-1999, 19992007, and 1999-2011. Our specifications below stack either the first two subperiods, or the first and third subperiods. As in AADHP, we use the operator " $\Delta$ " to denote the annualized change of a variable times 100 . Hence, for any variable $X$ we define its annual change during subperiod $\tau$, $\Delta X_{\tau}$, as

$$
\Delta X_{\tau}=\lambda_{\tau}\left(X_{t_{\tau, \text { end }}}-X_{t_{\tau, \text { start }}}\right)
$$

where $\lambda_{\tau}=\frac{100}{t_{\tau, \text { end }}-t_{\tau, \text { start }}}$ is the annualizing factor, $t_{\tau \text {,end }}$ is the end-year of subperiod $\tau$, and $t_{\tau, \text { start }}$ is the start-year of subperiod $\tau$. It is always the case that $\tau \in\{1,2\}$, where subperiod 1 corresponds 
to 1992-1999, and subperiod 2 corresponds to either 1999-2007 or 1999-2011.

To construct AADHP's measure of direct Chinese import exposure for the 392 manufacturing industries, we begin by defining Chinese import penetration in industry $j$ at year $t$ as

$$
I P_{j t}=\frac{\mathbb{M}_{j t}^{C}}{\mathbb{Y}_{j 91}+\mathbb{M}_{j 91}-\mathbb{X}_{j 91}},
$$

where $\mathbb{M}_{j t}^{C}$ represents real U.S. imports from China in industry $j$ at year $t$, and $\mathbb{Y}_{j 91}+\mathbb{M}_{j 91}-\mathbb{X}_{j 91}$ is real domestic absorption of U.S. industry $j$ (the industry's real output, plus real imports, less real exports) in $1991 .^{8}$ An increase in $I P_{j t}$ over time indicates tougher competition from China, and thus, larger changes in $I P_{j t}$ are related to higher Chinese import exposure. The measure of Chinese import exposure in industry $j$ during subperiod $\tau$-our first measure of the China shock - is then given by the annual change in import penetration, $\Delta I P_{j \tau}$; that is,

$$
\Delta I P_{j \tau}=\frac{\Delta \mathbf{M}_{j \tau}^{C}}{\mathbb{Y}_{j 91}+\mathbb{M}_{j 91}-\mathbb{X}_{j 91}}
$$

As in Autor, Dorn, and Hanson (2013), AADHP refer to the China shock as a Chinese supply shock to the rest of the world, and thus construct an instrument that attempts to isolate the Chinese supply effects captured by $\Delta I P_{j \tau}$. To get rid of potential U.S. domestic shocks that increase U.S. demand for Chinese imports, AADHP use as an instrumental variable for $\Delta I P_{j \tau}$ the sum of Chinese exports to other high-income countries. In particular, the instrument is defined as $\Delta I P_{j \tau}^{*}$, where

$$
I P_{j t}^{*}=\frac{\mathbf{M}_{j t}^{C *}}{\mathbb{Y}_{j 88}+\mathbb{M}_{j 88}-\mathbb{X}_{j 88}}
$$

is the sum of eight high-income countries' real imports from China in year $t, \mathrm{M}_{j t}^{C *}$, relative to 1988 U.S. real domestic absorption.

\subsection{China's PNTR Status}

As noted by PS, although U.S. tariffs imposed on Chinese goods were low - at most-preferred-nation levels - since the 1980s, they had to be renewed every year by the U.S. Congress, which created a latent threat for U.S.-China trade: facing uncertainty of renewal every year, firms in both countries were not willing to engage in long-lasting trade relationships as they would be facing very high tariff rates in case of non-renewal. This year-to-year uncertainty was removed in October 2000, when the U.S. Congress granted PNTR status to China to begin with its accession to the World Trade Organization (WTO) in December 2001.

\footnotetext{
${ }^{8}$ Nominal imports and exports data is gathered from the United Nations COMTRADE database, and nominal output is given by the value of shipments from the NBER productivity database. To calculate real values, AADHP deflate using the Personal Consumption Expenditure Price Index (PCE) of the Bureau of Economic Analysis (BEA).
} 
PS argue that the elimination of the uncertainty would affect U.S.-China trade along several channels, from giving U.S. firms incentives to relocate and invest in China, to encouraging Chinese firms to expand more aggressively in the U.S. market. The key insight of PS was that the latent threat of non-renewal was more serious in industries that were facing a larger potential tariff increase. Hence, the granting of PNTR status to China is likely to have a larger impact on those industries that had a larger NTR gap - the difference between the non-renewal tariff and the Normal Trade Relations (NTR) tariff-as these industries were subject to higher uncertainty levels before the trade policy change. Following this insight, PS exploit cross-industry variation in NTR gaps in the manufacturing sector, and show that granting PNTR status to China caused a 15 percent decline in U.S. manufacturing employment by 2007.

In the construction of the NTR gaps for our 392 manufacturing industries, we begin with the NTR gaps provided by PS for Harmonized System (HS) 'families.' PS create these families using an algorithm developed in Pierce and Schott (2012a) which yields time-consistent industry codes that account for the transition from SIC to NAICS in 1997, and the subsequent NAICS revisions in 2002 and $2007 .^{9}$ From the HS time-consistent families, we use the concordances provided by PS to map families into SIC codes, taking the average across the (HS) NTR gaps that match each SIC code. Finally, we use the concordance table of Autor, Dorn, and Hanson (2013) that maps four-digit SIC codes to the final AADHP's 392 manufacturing industries.

Letting $G A P_{j}$ denote the NTR gap of industry $j$, we define the PNTR-status variable in subperiod $\tau$ as

$$
P N T R_{j \tau}=G A P_{j} \times \lambda_{\tau} \times \mathbb{1}\{\tau=2\},
$$

where $\mathbb{1}\{\tau=2\}$ is a dummy variable taking the value of 1 for the second period, and is zero otherwise. Hence, $P N T R_{j \tau}$ is zero for every industry during the 1992-1999 period, and equals an annualized version of $G A P_{j}$ for either $1999-2007$ or $1999-2011 .{ }^{10}$ The variable $P N T R_{j \tau}$ serves as our second measure of the China shock.

\section{Industry-Level Analysis}

We start by looking at the responses of manufacturing industry-level employment to the China shock. Then we expand the industry-level analysis to include non-manufacturing industries and

\footnotetext{
${ }^{9}$ To construct their NTR gaps, PS use non-NTR and NTR tariff rates in 1999, which are obtained at the HS eight-digit level from the tariff database of Feenstra, Romalis, and Schott (2002). Then they use their algorithm from Pierce and Schott (2012a) to map HS eight-digit NTR gaps to their time-consistent HS families, and lastly they map these families to their NAICS classification using concordances from the BEA.

${ }^{10}$ We multiply $G A P_{j}$ times $\lambda_{\tau}$ for convenience in the scaling of the estimated coefficients in our empirical analysis below. Suppressing $\lambda_{\tau}$ does not have any impact in the interpretation of the results.
} 
upstream and downstream linkages across industries.

\subsection{Manufacturing Employment and the China Shock}

This section looks exclusively at manufacturing employmxponses to the China shock. Hence, we aggregate job flows across all commuting zones for each of the 392 manufacturing industries. Thus, the specification to study the impact of the China shock on U.S. manufacturing net employment is

$$
\Delta \ln L_{j \tau}=\alpha_{\tau}+\beta S_{j \tau}+\eta Z_{j}+\varepsilon_{j \tau}
$$

where for industry $j$ during subperiod $\tau, \Delta \ln L_{j \tau}$ is the annual change in log employment, and $S_{j \tau}$ is the China shock variable, measured as either $\Delta I P_{j \tau}$ in (1) or $P N T R_{j \tau}$ in (2). The term $\alpha_{\tau}$ denotes a subperiod fixed effect, $Z_{j}$ is a vector of time-invariant industry-level controls, and $\varepsilon_{j \tau}$ is the error term.

The annual change in industry $j$ 's log employment can be split into its job-flow components. In particular, given that the employment change in industry $j$ during subperiod $\tau$ is due to establishments' expansions, contractions, births and deaths, we can write $\Delta \ln L_{j \tau}$ as

$$
\Delta \ln L_{j \tau} \equiv b_{j \tau}-d_{j \tau}+e_{j \tau}-c_{j \tau}
$$

where $b_{j \tau}$ denotes the contribution of births to the industry's log employment change, and the same for deaths $\left(d_{j \tau}\right)$, expansions $\left(e_{j \tau}\right)$, and contractions $\left(c_{j \tau}\right)$. We calculate $b_{j \tau}$ as

$$
b_{j \tau} \equiv \lambda_{\tau}\left(\frac{B_{j \tau}}{\Delta L_{j \tau}}\right) \Delta \ln L_{j \tau},
$$

with analogous expressions for $d_{j \tau}, e_{j \tau}$, and $c_{j \tau}$.

Thus, for each job flow we estimate

$$
F_{j \tau}=\alpha_{\tau}^{F}+\beta^{F} S_{j \tau}+\eta^{F} Z_{j}+\varepsilon_{j \tau}^{F}
$$

where $F_{j \tau} \in\left\{b_{j \tau}, d_{j \tau}, e_{j \tau}, c_{j \tau}, b_{j \tau}-d_{j \tau}, e_{j \tau}-c_{j \tau}, b_{j \tau}+e_{j \tau}, d_{j \tau}+c_{j \tau}\right\}$. Note that we also estimate the impact of the China shock on the net extensive margin of employment, $b_{j \tau}-d_{j \tau}$, the net intensive margin of employment, $e_{j \tau}-c_{j \tau}$, gross job creation, $b_{j \tau}+e_{j \tau}$, and on gross job destruction, $d_{j \tau}+c_{j \tau}$. By construction, linear combinations of the China-shock coefficients from (4) must be equivalent to the China-shock coefficient from the regression of the log-employment annual change in (3). That is, it must always be the case that

$$
\beta \equiv \beta^{b}-\beta^{d}+\beta^{e}-\beta^{c} \equiv \beta^{b-d}+\beta^{e-c} \equiv \beta^{b+e}-\beta^{d+c} .
$$


Table 1 presents our industry-level results for the manufacturing sector. All regressions include 392 manufacturing industries, subperiod fixed effects, and are weighted by 1992 employment, but differ in their China-shock regressor, period coverage, and estimation method. Each estimated coefficient represents the China-shock outcome of a regression, with standard errors clustered at the three-digit SIC level. The first row shows $\hat{\beta}$ from the estimation of (3), while the following rows show $\hat{\beta}^{F}$ from the estimation of (4), for $F \in\{b, d, e, c, b-d, e-c, b+e, d+c\}$. To provide a comparison with the net employment results using the NETS data, we also estimate equation (3) using AADHP's CBP data.

In Table 1 and throughout the paper, we treat 1992-2007 as our benchmark period because this makes the lengths of our subperiods, 1992-1999 and 1999-2007, more similar (the first subperiod is a seven-year difference and the second is an eight-year difference). This is important when doing a job-flows analysis because longer time periods will generally increase the importance of the extensive margin of employment (births and deaths). This implies that when splitting the 1992-2011 period into a seven-year difference and a twelve-year difference (for the 1999-2011 subperiod), we likely exaggerate the importance of the extensive margin in the second subperiod. ${ }^{11}$ Nevertheless, in the estimation of all the specifications in this paper, the main results of the 1992-2007 regressions are always qualitatively similar to those of the 1992-2011 regressions.

Columns 1-5 use Chinese import exposure as the China-shock regressor. Columns 1 and 2 use the 1992-2007 period but differ in their estimation method. They show that OLS and IV results are very similar in sign and statistical significance, but the IV net growth coefficients using either NETS or CBP data are more than 1.6 times larger than the OLS coefficients. For the rest of the paper, we focus exclusively on IV estimation results when using Chinese import exposure as the China-shock regressor. As in AADHP, an increase in Chinese import penetration is associated with net job destruction. The most important result in column 2 , however, comes from the analysis of the job-flow coefficients. Note that increases in job destruction by deaths and contractions significantly matter for explaining the effects on net employment growth, but deaths are far more important. On the other hand, the coefficients on births and expansions are very close to zero. Column 5 shows that the results barely change if we expand the second subperiod to include the Great Recession

\footnotetext{
${ }^{11}$ Longer time periods may also miss substantial shorter-term job creation and destruction on both the intensive and extensive margins. For example, for the twelve-year difference from 1999 to 2011, expansions and contractions of employment would be calculated only for those establishments that are active in both periods, job flows from deaths would be calculated as the sum of 1999 employment of all the firms that were active in that year but no longer alive in 2011, and job flows due to births would be the sum of 2011 employment of all the firms that are active in that year but that did not exist in 1999. Hence, we would be missing the employment action of the survivors in the middle of the period, but also we would be missing all those firms that were born born after 1999 but that never made it to 2011.
} 
Table 1: Effects of the China Shock on Manufacturing Employment

\begin{tabular}{|c|c|c|c|c|c|c|c|}
\hline & \multicolumn{5}{|c|}{ Chinese Import Exposure } & \multicolumn{2}{|c|}{ PNTR Status } \\
\hline & $\begin{array}{c}\text { 1992-2007 } \\
\text { (1) }\end{array}$ & $\begin{array}{c}\text { 1992-2007 } \\
(2)\end{array}$ & $\begin{array}{c}\text { 1992-1999 } \\
(3)\end{array}$ & $\begin{array}{c}1999-2007 \\
(4)\end{array}$ & $\begin{array}{c}\text { 1992-2011 } \\
(5)\end{array}$ & $\begin{array}{c}\text { 1992-2007 } \\
(6)\end{array}$ & $\begin{array}{c}\text { 1992-2011 } \\
(7)\end{array}$ \\
\hline Net employment growth & $\begin{array}{c}-0.27^{* *} \\
(0.11)\end{array}$ & $\begin{array}{c}-0.45^{* * *} \\
(0.16)\end{array}$ & $\begin{array}{l}-0.90^{*} \\
(0.51)\end{array}$ & $\begin{array}{c}-0.41^{* *} \\
(0.16)\end{array}$ & $\begin{array}{c}-0.46^{* * *} \\
(0.17)\end{array}$ & $\begin{array}{c}-0.29 * * * \\
(0.09)\end{array}$ & $\begin{array}{c}-0.36^{* * *} \\
(0.13)\end{array}$ \\
\hline \multicolumn{8}{|l|}{ Job Flows } \\
\hline Births & $\begin{array}{c}0.01 \\
(0.03)\end{array}$ & $\begin{array}{c}0.01 \\
(0.03)\end{array}$ & $\begin{array}{c}0.14 \\
(0.14)\end{array}$ & $\begin{array}{l}-0.00 \\
(0.03)\end{array}$ & $\begin{array}{l}-0.01 \\
(0.06)\end{array}$ & $\begin{array}{l}-0.02 \\
(0.03)\end{array}$ & $\begin{array}{l}-0.00 \\
(0.06)\end{array}$ \\
\hline Deaths & $\begin{array}{c}0.22^{* * *} \\
(0.07)\end{array}$ & $\begin{array}{c}0.35^{* * *} \\
(0.11)\end{array}$ & $\begin{array}{c}0.89^{* * *} \\
(0.32)\end{array}$ & $\begin{array}{c}0.29^{* * *} \\
(0.10)\end{array}$ & $\begin{array}{c}0.38^{* * *} \\
(0.11)\end{array}$ & $\begin{array}{c}0.22^{* * *} \\
(0.05)\end{array}$ & $\begin{array}{c}0.35^{* * *} \\
(0.09)\end{array}$ \\
\hline Expansions & $\begin{array}{l}0.03^{*} \\
(0.01)\end{array}$ & $\begin{array}{c}0.01 \\
(0.02)\end{array}$ & $\begin{array}{c}0.03 \\
(0.13)\end{array}$ & $\begin{array}{c}0.00 \\
(0.02)\end{array}$ & $\begin{array}{c}0.02 \\
(0.02)\end{array}$ & $\begin{array}{l}-0.03 \\
(0.02)\end{array}$ & $\begin{array}{l}-0.01 \\
(0.02)\end{array}$ \\
\hline Contractions & $\begin{array}{c}0.09 \\
(0.05)\end{array}$ & $\begin{array}{l}0.12^{*} \\
(0.07)\end{array}$ & $\begin{array}{l}0.19^{*} \\
(0.11)\end{array}$ & $\begin{array}{l}0.12^{*} \\
(0.07)\end{array}$ & $\begin{array}{l}0.09^{*} \\
(0.05)\end{array}$ & $\begin{array}{c}0.02 \\
(0.04)\end{array}$ & $\begin{array}{l}-0.01 \\
(0.04)\end{array}$ \\
\hline Net extensive margin & $\begin{array}{c}-0.21 * * * \\
(0.06)\end{array}$ & $\begin{array}{c}-0.34^{* * *} \\
(0.11)\end{array}$ & $\begin{array}{c}-0.74^{* *} \\
(0.36)\end{array}$ & $\begin{array}{c}-0.29 * * * \\
(0.10)\end{array}$ & $\begin{array}{c}-0.39 * * * \\
(0.14)\end{array}$ & $\begin{array}{c}-0.24 * * * \\
(0.06)\end{array}$ & $\begin{array}{c}-0.35^{* * *} \\
(0.11)\end{array}$ \\
\hline Net intensive margin & $\begin{array}{l}-0.06 \\
(0.06)\end{array}$ & $\begin{array}{l}-0.12 \\
(0.08)\end{array}$ & $\begin{array}{l}-0.16 \\
(0.21)\end{array}$ & $\begin{array}{l}-0.11 \\
(0.08)\end{array}$ & $\begin{array}{l}-0.07 \\
(0.06)\end{array}$ & $\begin{array}{l}-0.05 \\
(0.05)\end{array}$ & $\begin{array}{l}-0.01 \\
(0.06)\end{array}$ \\
\hline Job creation & $\begin{array}{c}0.03 \\
(0.03)\end{array}$ & $\begin{array}{c}0.02 \\
(0.04)\end{array}$ & $\begin{array}{c}0.18 \\
(0.21)\end{array}$ & $\begin{array}{c}0.00 \\
(0.04)\end{array}$ & $\begin{array}{c}0.01 \\
(0.07)\end{array}$ & $\begin{array}{l}-0.05 \\
(0.04)\end{array}$ & $\begin{array}{l}-0.02 \\
(0.06)\end{array}$ \\
\hline Job destruction & $\begin{array}{c}0.31^{* * *} \\
(0.11)\end{array}$ & $\begin{array}{c}0.47^{* * *} \\
(0.15)\end{array}$ & $\begin{array}{c}1.08^{* * *} \\
(0.37)\end{array}$ & $\begin{array}{c}0.41^{* * *} \\
(0.14)\end{array}$ & $\begin{array}{c}0.47^{* * *} \\
(0.13)\end{array}$ & $\begin{array}{c}0.24^{* * *} \\
(0.08)\end{array}$ & $\begin{array}{c}0.34^{* * *} \\
(0.10)\end{array}$ \\
\hline \multicolumn{8}{|l|}{ CBP data: } \\
\hline Net employment growth & $\begin{array}{c}-0.68^{* * *} \\
(0.18)\end{array}$ & $\begin{array}{c}-1.26^{* * *} \\
(0.40)\end{array}$ & $\begin{array}{c}-2.37^{*} \\
(1.37)\end{array}$ & $\begin{array}{c}-1.15^{* * *} \\
(0.35)\end{array}$ & $\begin{array}{c}-1.33^{* * *} \\
(0.44)\end{array}$ & $\begin{array}{c}-0.94^{* * *} \\
(0.20)\end{array}$ & $\begin{array}{c}-1.26^{* * *} \\
(0.27)\end{array}$ \\
\hline Estimation method & OLS & IV & IV & IV & IV & OLS & OLS \\
\hline Observations & 784 & 784 & 392 & 392 & 784 & 784 & 784 \\
\hline
\end{tabular}

Notes: This table reports $\hat{\beta}$ and $\hat{\beta}^{F}$ from the estimation of specifications (3) and (4) for the manufacturing sector (392 industries). Regressions in columns 1, 2, and 5-7 include two subperiods, 1992-1999 and either 1999-2007 or 1999-2011, and regressions in columns 3 and 4 include only the subperiod indicated in the top of the column. All regressions include subperiod fixed effects (not reported) and are weighted by 1992 employment. The net growth regression with CBP data is weighted by 1992 CBP employment and is reported for the purpose of comparison with the net growth regression with NETS data. Standard errors (in parentheses) are clustered at the three-digit industry level. The coefficients are statistically significant at the $* 10 \%, * * 5 \%$, or $* * * 1 \%$ level. 
years.

To properly quantify the importance of establishment deaths due to the China shock, we calculate the estimated share of deaths in total Chinese-induced job reallocation. Denoting the estimated death share with $\hat{\delta}$, we calculate it as

$$
\hat{\delta} \equiv \frac{\left|\hat{\beta}^{d}\right|}{\left|\hat{\beta}^{b}\right|+\left|\hat{\beta}^{d}\right|+\left|\hat{\beta}^{e}\right|+\left|\hat{\beta}^{c}\right|} .
$$

As shown in the last column of Table 2, which presents predicted job reallocation along each jobflow type for the main specifications in this paper as well as their estimated death shares, the values of $\hat{\delta}$ from columns 2 and 5 are 0.71 and 0.76 , respectively. Thus, deaths of establishments account for more than 70 percent of total job reallocation induced by Chinese import exposure.

Columns 3 and 4 separately estimate the impact of Chinese import exposure in each of the subperiods. The same story holds but the magnitudes of the net and death coefficients are more than twice as large when using the 1992-1999 subperiod. This, however, does not imply that there was more Chinese-induced job destruction in the first period, as changes in Chinese import penetration during the 1990s were small compared to changes in the 2000s.

Columns 6 and 7 use the PNTR status as the China-shock regressor. PS make a strong case for the exogeneity of the PNTR-status regressor; thus, all the PNTR specifications in this paper are estimated by OLS. ${ }^{12}$ Notably, the results from columns 6 and 7 are very similar to those obtained using Chinese import exposure. The only difference is that the coefficient on contractions is no longer significant in the PNTR regressions. But the main message remains: deaths of establishments are by far the main driver of Chinese-induced job reallocation, with estimated death shares of 0.76 from column 6 and 0.95 from column 7 (see the values for $\hat{\delta}$ in panel B of Table 2).

Our PNTR net-employment-growth results are qualitatively similar to those obtained by PS using the Longitudinal Business Database. Moreover, their working paper version includes a brief job flows analysis that splits employment changes into their job creation and job destruction components. For the 2001-2007 period, they find that job destruction accounts for more than 80 percent of total job reallocation induced by China's PNTR status (see Figure 4 in Pierce and Schott, 2012b). With remarkable similarity, in our case (from column 6 in Table 1) the estimated share of job destruction in total job reallocation is 83 percent.

\footnotetext{
${ }^{12}$ In their robustness checks, PS perform an IV estimation using the non-NTR tariff rates of 1930 to instrument, and an OLS estimation using 1990 tariffs (instead of the 1999 tariffs). In both cases, their results for the impact of PNTR-status on employment become stronger.
} 
Table 2: Predicted U.S. Employment Changes due to the China Shock (in Thousands) and the Estimated Death Share

\begin{tabular}{|c|c|c|c|c|c|c|c|}
\hline Specification & Exposure type-Sector & Net change & Births & Deaths & Expan. & Contr. & $\hat{\delta}$ \\
\hline \multicolumn{8}{|c|}{ A. Chinese import exposure } \\
\hline \multicolumn{8}{|l|}{ 1992-2007: } \\
\hline Table 1 , col. 2 & Direct-Manufacturing & -477 & 11 & -371 & 11 & -127 & 0.71 \\
\hline Table 4 , col. 2 & Combined I-Total & -759 & 52 & -638 & 17 & -190 & 0.71 \\
\hline Table 4 , col. 5 & Combined II-Total & -888 & 137 & -820 & 68 & -273 & 0.63 \\
\hline Table 6 , col. 1 & Local-Exposed & $-2,128$ & 580 & $-2,167$ & 329 & -871 & 0.55 \\
\hline Table 6 , col. 2 & Nonexposed tradable & 198 & -258 & 198 & -218 & 476 & 0.17 \\
\hline Table 6 , col. 3 & Nonexposed nontrad. & 2,225 & 3,772 & $-2,476$ & 967 & -39 & 0.34 \\
\hline \multicolumn{8}{|l|}{ 1992-2011: } \\
\hline Table 1 , col. 5 & Direct-Manufacturing & -491 & -11 & -406 & 21 & -96 & 0.76 \\
\hline Table 4 , col. 3 & Combined I-Total & -880 & 0 & -788 & 55 & -147 & 0.80 \\
\hline Table 4 , col. 6 & Combined II-Total & -999 & 100 & $-1,024$ & 125 & -200 & 0.71 \\
\hline Table A.5, col. 1 & Local-Exposed & $-2,515$ & 427 & $-2,358$ & 0 & -584 & 0.70 \\
\hline Table A.5, col. 2 & Nonexposed tradable & 114 & -297 & 388 & -320 & 343 & 0.29 \\
\hline Table A.5, col. 3 & Nonexposed nontrad. & 2,222 & 4,285 & $-2,630$ & 1,043 & -476 & 0.31 \\
\hline
\end{tabular}

1992-2007:

Table 1, col. 6

Table 5, col. 2

Table 5 , col. 5

Table 7, col. 1

Table 7, col. 2

Table 7, col. 3

1992-2011:

Table 1, col. 7

Table 5, col. 3

Table 5, col. 6

Table A.6, col. 1

Table A.6, col. 2

Table A.6, col. 3

\section{B. PNTR status}

\begin{tabular}{|c|c|c|c|c|c|c|}
\hline Direct-Manufacturing & $-1,496$ & -103 & $-1,135$ & -155 & -103 & 0.76 \\
\hline Combined I-Total & $-2,484$ & 184 & $-2,484$ & -92 & -92 & 0.87 \\
\hline Combined II-Total & $-2,825$ & 404 & $-2,959$ & -135 & -135 & 0.8 \\
\hline Local-Exposed & $-3,896$ & -173 & $-2,857$ & 173 & $-1,039$ & \\
\hline Nonexposed tradable & -662 & 0 & -496 & 0 & -165 & \\
\hline Nonexposed nontrad. & 2,792 & 4,101 & $-2,356$ & 1,221 & -174 & \\
\hline Direct-Manufacturing & $-1,707$ & 0 & $-1,707$ & -47 & 47 & \\
\hline Combined I-Total & $-3,693$ & 0 & $-3,779$ & 0 & 86 & \\
\hline Combined II-Total & $-5,261$ & -385 & $-5,132$ & 128 & 128 & \\
\hline Local-Exposed & $-6,620$ & $-1,179$ & $-4,262$ & $-1,179$ & 0 & \\
\hline Nonexposed tradable & $-1,269$ & -85 & -846 & -169 & 169 & \\
\hline Nonexposed nontrad. & 4,693 & 5,595 & $-3,610$ & 3,519 & -812 & \\
\hline
\end{tabular}

Notes: Reported quantities represent the change in employment attributed to changes in Chinese import exposure (in Panel A) or to China's PNTR status (in Panel B) for the specifications described in the first column. Negative values indicate that the China-shock variable reduces employment. Equations (6) and (7) show general formulas to calculate predicted employment changes from Tables 1, 4, and 5, and equations (16) and (17) show the general formulas to calculate predicted employment changes from Tables 6 and 7 . The numbers in bold denote predicted changes corresponding to statistically significant coefficients in the corresponding tables. For each specification, the last column shows the estimated share of deaths in total Chinese-induced job reallocation, $\hat{\delta}$, as defined in (5). 


\subsubsection{Predicted Employment Changes}

To calculate predicted employment changes, we use the counterfactual formula of Autor, Dorn, and Hanson (2013) and AADHP, and its equivalent for the PNTR specifications. Therefore, for the Chinese-import-exposure specifications we calculate predicted employment changes for the 19922007 period as

$$
\text { Predicted employment change }(I P)=\sum_{j}\left[1-e^{-\hat{\beta} \rho\left(I P_{j 07}-I P_{j 92}\right)}\right] L_{j 07},
$$

where $\hat{\beta}$ is either the NETS or CBP coefficient from the net growth regression in column $2, L_{j 07}$ is either the NETS or CBP employment in industry $j$ in 2007, and $\rho$ is the partial $R$-squared from the first-stage regression of $\Delta I P_{j \tau}$ on $\Delta I P_{j \tau}^{*}$ (the value of $\rho$ is 0.66 when using the NETS data and 0.60 when using the CBP data). On the other hand, the predicted employment change up to 2007 from the PNTR-status specifications is given by

$$
\text { Predicted employment change }(P N T R)=\sum_{j}\left[1-e^{-\hat{\beta}\left(G A P_{j}\right)}\right] L_{j 07},
$$

where $\hat{\beta}$ is either the NETS or CBP coefficient from the net growth regression in column 6 , and $G A P_{j}$ is the NTR gap for industry $j$. Analogous formulas are used to calculate predicted employment changes up to 2011.

Table 2 shows predicted employment changes - from births, deaths, expansions, contractions, and the net change - for columns 2, 5, 6, and 7 of Table 1 . The Chinese-import-exposure specifications predict losses in the U.S. manufacturing sector of 0.48 million during 1992-2007 and 0.49 million during 1992-2011. The PNTR specifications, however, predict much higher manufacturing net losses as a consequence of China's PNTR status: about 1.5 million jobs losses up to 2007, and about 1.7 million losses up to 2011. The difference is more dramatic if we consider that the losses driven by import exposure occur since 1992, while the PNTR-driven losses occur in the 2000s.

These differences in net losses are not unique to this paper. AADHP obtain net losses of 0.85 million jobs in manufacturing during 1991-2007 due to Chinese import exposure, while PS estimate a 15 percent decline in manufacturing employment due to China's PNTR status, which corresponds to about 2.7 million jobs. Although explaining the sources of this discrepancy is beyond the scope of this paper, a simple explanation is that the AADHP approach only considers the China supply effect (a competition effect), while the PS approach may capture more channels of action such as the large increase in offshoring possibilities. In spite of this, our results show that both approaches give the same message: Chinese-induced net losses in U.S. manufacturing employment are mainly driven by deaths of establishments. 
Comparing the net-employment-growth results from the NETS data in the first row of Table 1 to the net growth results from the CBP data of AADHP in the last row, we see that they are similar in sign and statistical significance but they differ in magnitude. In the Chinese-importexposure columns, the $\hat{\beta}$ 's from CBP are between 2.5 and 2.9 times larger in magnitude than the $\hat{\beta}$ 's from NETS, while in the PNTR-status columns the CBP coefficients are between 3.2 and 3.5 times larger. This does not imply, however, that predicted employment losses are between 2.5 and 3.5 times larger when using CBP data, as NETS reports more employment than CBP. For an appropriate comparison, Table A.2 in the Appendix shows the predicted net employment changes from Table 1's columns 2, 5,6 and 7 under each dataset.

Indeed, predicted net employment losses are much larger with the CBP data: between 1.6 and 1.8 times larger for the import-exposure specifications, and about 2.8 times larger for the PNTRstatus specifications. This discrepancy may be due to remnant effects of the NETS data stickiness described above, or simply due to idiosyncratic characteristics of each dataset.

\subsubsection{Robustness}

As robustness checks, Table 3 builds on columns 2, 5, 6, and 7 from Table 1 by adding industrylevel time-invariant controls proposed by AADHP. These are: (i) ten one-digit manufacturing sector dummies (manufacturing sector controls), (ii) 1991 levels of the share of production workers in total industry employment, the log average wage, and the ratio of capital to value-added, as well as 1990 levels of the share of computer investment in total investment, and the share of high-tech equipment in total investment (production controls), (iii) 1976-91 changes in the log average wage and in the share of the industry's employment in total U.S. employment (pretrend controls), and (iv) industry fixed effects.

Columns 1, 2, 4, and 5 indicate that when adding manufacturing sector, production, and pretrend controls, the coefficients for the net growth regressions remains statistically significant. The Chinese-import-exposure results on job flows in columns 1 and 2 tell the same story as before: job destruction by deaths is the main driver of the net employment decline associated with Chinese import exposure during the 1992-2007 and 1992-2011 periods (the corresponding values of $\hat{\delta}$ - the share of deaths in total Chinese-induced job reallocation - are 0.56 and 0.57). As well, the PNTR results on job flows in columns 4 and 5 continue to show death as the main driver of Chineseinduced job reallocation (with $\hat{\delta}$ values of 0.46 during 1992-2007 and 0.64 during 1992-2011), but also report statistically significant declines in births and expansions.

In comparison, columns $1,2,4$, and 5 show that the coefficients in the net-growth regressions using CBP data become closer to the NETS net coefficients when industry-level controls are added. 
Table 3: Estimation of the Effects of the China Shock on Manufacturing Employment with IndustryLevel Controls

\begin{tabular}{|c|c|c|c|c|c|c|}
\hline & \multicolumn{3}{|c|}{ Chinese Import Exposure } & \multicolumn{3}{|c|}{ PNTR Status } \\
\hline & $(1)$ & $(2)$ & $(3)$ & $(4)$ & $(5)$ & $(6)$ \\
\hline Net employment growth & $\begin{array}{c}-0.39^{* *} \\
(0.17)\end{array}$ & $\begin{array}{c}-0.35^{* *} \\
(0.16)\end{array}$ & $\begin{array}{l}-0.16 \\
(0.16)\end{array}$ & $\begin{array}{c}-0.22^{* * *} \\
(0.08)\end{array}$ & $\begin{array}{c}-0.24^{* *} \\
(0.10)\end{array}$ & $\begin{array}{c}-0.18^{*} \\
(0.10)\end{array}$ \\
\hline \multicolumn{7}{|l|}{ Job flows } \\
\hline Births & $\begin{array}{l}-0.03 \\
(0.03)\end{array}$ & $\begin{array}{l}-0.05 \\
(0.05)\end{array}$ & $\begin{array}{l}-0.09 \\
(0.06)\end{array}$ & $\begin{array}{l}-0.06^{*} \\
(0.03)\end{array}$ & $\begin{array}{l}-0.05 \\
(0.06)\end{array}$ & $\begin{array}{c}-0.09^{* *} \\
(0.04)\end{array}$ \\
\hline Deaths & $\begin{array}{c}0.22^{* *} \\
(0.09)\end{array}$ & $\begin{array}{c}0.20^{* *} \\
(0.08)\end{array}$ & $\begin{array}{c}0.03 \\
(0.07)\end{array}$ & $\begin{array}{c}0.10^{* *} \\
(0.04)\end{array}$ & $\begin{array}{c}0.16^{* *} \\
(0.07)\end{array}$ & $\begin{array}{l}0.04 \\
(0.04)\end{array}$ \\
\hline Expansions & $\begin{array}{l}-0.02 \\
(0.02)\end{array}$ & $\begin{array}{l}-0.00 \\
(0.02)\end{array}$ & $\begin{array}{c}0.01 \\
(0.03)\end{array}$ & $\begin{array}{c}-0.05^{* *} \\
(0.02)\end{array}$ & $\begin{array}{l}-0.05^{*} \\
(0.03)\end{array}$ & $\begin{array}{l}-0.06 \\
(0.04)\end{array}$ \\
\hline Contractions & $\begin{array}{l}0.12^{*} \\
(0.07)\end{array}$ & $\begin{array}{c}0.09 \\
(0.07)\end{array}$ & $\begin{array}{c}0.06 \\
(0.06)\end{array}$ & $\begin{array}{c}0.00 \\
(0.04)\end{array}$ & $\begin{array}{l}-0.01 \\
(0.04)\end{array}$ & $\begin{array}{l}-0.01 \\
(0.03)\end{array}$ \\
\hline Net extensive margin & $\begin{array}{c}-0.25^{* *} \\
(0.10)\end{array}$ & $\begin{array}{c}-0.25^{* *} \\
(0.10)\end{array}$ & $\begin{array}{l}-0.12 \\
(0.12)\end{array}$ & $\begin{array}{c}-0.16^{* * *} \\
(0.05)\end{array}$ & $\begin{array}{c}-0.21^{* *} \\
(0.08)\end{array}$ & $\begin{array}{c}-0.13^{* *} \\
(0.06)\end{array}$ \\
\hline Net intensive margin & $\begin{array}{l}-0.14 \\
(0.09)\end{array}$ & $\begin{array}{l}-0.10 \\
(0.08)\end{array}$ & $\begin{array}{l}-0.05 \\
(0.08)\end{array}$ & $\begin{array}{l}-0.05 \\
(0.05)\end{array}$ & $\begin{array}{l}-0.03 \\
(0.05)\end{array}$ & $\begin{array}{l}-0.05 \\
(0.06)\end{array}$ \\
\hline Job creation & $\begin{array}{l}-0.05 \\
(0.04)\end{array}$ & $\begin{array}{l}-0.05 \\
(0.06)\end{array}$ & $\begin{array}{l}-0.08 \\
(0.08)\end{array}$ & $\begin{array}{c}-0.11^{* * *} \\
(0.04)\end{array}$ & $\begin{array}{l}-0.10^{*} \\
(0.06)\end{array}$ & $\begin{array}{c}-0.15^{* *} \\
(0.06)\end{array}$ \\
\hline Job destruction & $\begin{array}{c}0.34^{* *} \\
(0.14)\end{array}$ & $\begin{array}{c}0.30^{* *} \\
(0.12)\end{array}$ & $\begin{array}{c}0.09 \\
(0.11)\end{array}$ & $\begin{array}{c}0.11 \\
(0.07)\end{array}$ & $\begin{array}{c}0.15 \\
(0.09)\end{array}$ & $\begin{array}{c}0.02 \\
(0.06)\end{array}$ \\
\hline \multicolumn{7}{|l|}{ CBP data: } \\
\hline Net employment growth & $\begin{array}{c}-0.84^{* * *} \\
(0.26)\end{array}$ & $\begin{array}{c}-0.76^{* * *} \\
(0.23)\end{array}$ & $\begin{array}{c}-0.87^{* *} \\
(0.36)\end{array}$ & $\begin{array}{c}-0.55^{* * *} \\
(0.14)\end{array}$ & $\begin{array}{c}-0.70^{* * *} \\
(0.20)\end{array}$ & $\begin{array}{c}-0.70^{* * *} \\
(0.15)\end{array}$ \\
\hline Estimation method & IV & IV & IV & OLS & OLS & OLS \\
\hline Manf. sector controls & Yes & Yes & No & Yes & Yes & No \\
\hline Production controls & Yes & Yes & No & Yes & Yes & No \\
\hline Pretrend controls & Yes & Yes & No & Yes & Yes & No \\
\hline Industry fixed effects & No & No & Yes & No & No & Yes \\
\hline Include 2008-2011 & No & Yes & No & No & Yes & No \\
\hline Observations & 784 & 784 & 784 & 784 & 784 & 784 \\
\hline
\end{tabular}

Notes: This table reports $\hat{\beta}$ and $\hat{\beta}^{F}$ from the estimation of specifications (3) and (4) for the manufacturing sector (392 industries) including industry-level time invariant controls. All regressions include two subperiods, 1992-1999 and either 1999-2007 (in columns 1, 3, 4 and 6) or 1999-2011 (in columns 2 and 5). All regressions include subperiod fixed effects (not reported) and are weighted by 1992 employment. The net growth regression with CBP data is weighted by 1992 CBP employment, and is reported for the purpose of comparison with the net growth regression with NETS data. Standard errors (in parentheses) are clustered at the three-digit industry level. The coefficients are statistically significant at the *10\%, $* * 5 \%$, or $* * * 1 \%$ level.

An important caveat is the outcome of the industry fixed-effects regressions with NETS data in column 3 and 6, which show the coefficients on deaths losing their statistical significance, along with the Chinese-import-exposure coefficient in the net-employment-growth regression. Given that the specifications are already in first differences, the results in columns 3 and 6 suggest important 
industry-level trends in the NETS data that can be hard to disentangle from the effects of import competition. Given that our main results hold when we include the pretrend controls, we do not think that these latter results undermine our conclusions. Moreover, we believe there are a few reasons the specifications with industry-specific trends may be less informative about the China shock. First, as AADHP suggest, effects within industry can be weakened by the exacerbation of measurement error within narrow industry cells. Second, weaker within-industry results can reflect other firms in the same industry responding to prior and anticipated import competition, so that it can be particularly hard to identify the timing of the effect of import competition from the within-industry data. Finally, recent work in the minimum wage literature has emphasized that it can be very hard to distinguish between a treatment effect and unit-specific time trends when much of the effect of the treatment is on changes or growth rates, rather than levels (Meer and West, 2016).

\subsection{Upstream and Downstream Sectoral Linkages}

This section considers input-output linkages across industries. Following PS, AAHDP argue that upstream and downstream linkages across industries can increase or decrease the impact of the China shock on U.S. employment. Upstream linkages refer to effects flowing upward from a purchasing industry to a selling industry: if an industry is negatively affected by the China shock, it will decrease its purchases and hence negatively affect providing industries. Hence, it is expected that an increase in upstream Chinese exposure drives down an industry's employment. Downstream linkages, on the other hand, refer to effects flowing downward from a selling industry to a purchasing industry: if an industry contracts due to higher Chinese exposure, purchasing industries have less access to domestic inputs, which may cause them to contract too; however, these displaced domestic inputs may be replaced by cheaper Chinese inputs, which has a countervailing impact on purchasing industries. Thus, an increase in downstream Chinese exposure may decrease or increase an industry's employment. ${ }^{13}$

Most of non-manufacturing firms are non-importing industries and therefore, they do not have an associated direct import penetration measure as defined in section 4.1, nor an associated NTR gap as defined in section 4.2. However, these non-importing non-manufacturing industries purchase inputs from and sell goods to importing industries with associated NTR gaps. Hence, a benefit of the input-output approach is that we are able to obtain measures of indirect Chinese exposureresulting from both changes in Chinese import penetration for directly exposed industries and

\footnotetext{
${ }^{13} \mathrm{PS}$ and AADHP use opposite terminologies in the definition of upstream and downstream. Here we use the terminology of AADHP.
} 
China's PNTR status - for non-importing non-manufacturing industries.

\subsubsection{Upstream and Downstream Import Exposure}

To calculate upstream and downstream import exposure measures, which are weighted averages of the industries' direct import exposure measures, AADHP use the 1992 input-output table from the Bureau of Economic Analysis (BEA) as follows. If $\mu_{g j}$ denotes industry $g$ 's purchases from industry $j$, the share of industry $g$ in total sales of industry $j$ is given by $\omega_{g j}^{U}=\mu_{g j} / \sum_{g^{\prime}} \mu_{g^{\prime} j}$. Thus, the upstream Chinese import exposure measure for industry $j$ during subperiod $\tau$ is calculated as

$$
\Delta U I P_{j \tau}=\sum_{g} \omega_{g j}^{U} \Delta I P_{g \tau}
$$

where $I P_{g t}$ is the direct Chinese import exposure in industry $g$ as defined in (1). Similarly, the share of industry $g$ in total purchases of industry $j$ is $\omega_{j g}^{D}=\mu_{j g} / \sum_{g^{\prime}} \mu_{j g^{\prime}}$, so that the downstream Chinese import exposure measure for industry $j$ during subperiod $\tau$ is

$$
\Delta D I P_{j \tau}=\sum_{g} \omega_{j g}^{D} \Delta I P_{g \tau}
$$

The main analysis on input-output linkages of AADHP separately includes $\Delta I P_{j \tau}, \Delta U I P_{j \tau}$, and $\Delta D I P_{j \tau}$ as regressors in their net-employment-growth IV regressions, using $\Delta I P_{j \tau}^{*}, \Delta U I P_{j \tau}^{*}$, and $\Delta D I P_{j \tau}^{*}$ as instruments. ${ }^{14}$ Given that their estimated coefficient on $\Delta D I P_{j \tau}$ is not statistically significant in any of their specifications, they focus their discussion on predicted employment losses from specifications that only include $\Delta I P_{j \tau}$ and $\Delta U I P_{j \tau}$. As well, they estimate a specification that combines $\Delta I P_{j \tau}$ and $\Delta U I P_{j \tau}$ in a single measure, $\Delta I P_{j \tau}+\Delta U I P_{j \tau}$, which yields similar results to the specification that includes them separately.

To simplify our job flows analysis, here we follow the latter approach and focus on combined measures of Chinese import exposure. The first combined measure adds the direct and upstream measures, $\Delta I P_{j \tau}+\Delta U I P_{j \tau}$, while the second combined measure adds all three, $\Delta I P_{j \tau}+\Delta U I P_{j \tau}+$ $\Delta D I P_{j \tau}$. As in AADHP, instruments are included separately, using $\Delta I P_{j \tau}^{*}$ and $\Delta U I P_{j \tau}^{*}$ as instruments for the first measure, and adding $\Delta D I P_{j \tau}^{*}$ for the second measure. We also tried using as instruments $\Delta I P_{j \tau}^{*}+\Delta U I P_{j \tau}^{*}$ for the first measure, and $\Delta I P_{j \tau}^{*}+\Delta U I P_{j \tau}^{*}+\Delta D I P_{j \tau}^{*}$ for the second measure, with the results barely changing in magnitude and significance.

Pooling all manufacturing and non-manufacturing industries (a total of 479 industries) and two subperiods (1992-1999 and either 1999-2007 or 1999-2011), Table 4 presents our IV estimation results for the impact of combined measures of Chinese import exposure on net employment

\footnotetext{
${ }^{14}$ To construct $\Delta U I P_{j \tau}^{*}$ and $\Delta D I P_{j \tau}^{*}$, we simply have to replace $\Delta I P_{g \tau}$ with $\Delta I P_{g \tau}^{*}$ in (8) and (9).
} 
Table 4: IV Estimation of the Effects of Chinese Import Exposure on U.S. Employment — with Upstream and Downstream Linkages Across Industries

\begin{tabular}{|c|c|c|c|c|c|c|}
\hline & \multicolumn{3}{|c|}{$\begin{array}{c}\text { Combined measure I } \\
(\text { direct+upstream })\end{array}$} & \multicolumn{3}{|c|}{$\begin{array}{c}\text { Combined measure II } \\
\text { (direct+upstream +downstream) }\end{array}$} \\
\hline & $(1)$ & $(2)$ & $(3)$ & $(4)$ & $(5)$ & $(6)$ \\
\hline Net employment growth & $\begin{array}{c}-0.38^{* *} \\
(0.15)\end{array}$ & $\begin{array}{c}-0.44^{* * *} \\
(0.15)\end{array}$ & $\begin{array}{c}-0.47 * * * \\
(0.16)\end{array}$ & $\begin{array}{c}-0.33^{* *} \\
(0.14)\end{array}$ & $\begin{array}{c}-0.38^{* * *} \\
(0.13)\end{array}$ & $\begin{array}{c}-0.39 * * * \\
(0.11)\end{array}$ \\
\hline \multicolumn{7}{|l|}{ Job flows } \\
\hline Births & $\begin{array}{c}0.02 \\
(0.06)\end{array}$ & $\begin{array}{c}0.03 \\
(0.04)\end{array}$ & $\begin{array}{c}0.00 \\
(0.07)\end{array}$ & $\begin{array}{c}0.05 \\
(0.06)\end{array}$ & $\begin{array}{c}0.06 \\
(0.05)\end{array}$ & $\begin{array}{c}0.04 \\
(0.07)\end{array}$ \\
\hline Deaths & $\begin{array}{c}0.28 * * * \\
(0.09)\end{array}$ & $\begin{array}{c}0.37 * * * \\
(0.10)\end{array}$ & $\begin{array}{c}0.43^{* * *} \\
(0.11)\end{array}$ & $\begin{array}{c}0.30 * * * \\
(0.09)\end{array}$ & $\begin{array}{c}0.36^{* * *} \\
(0.09)\end{array}$ & $\begin{array}{c}0.41^{* * *} \\
(0.10)\end{array}$ \\
\hline Expansions & $\begin{array}{c}0.01 \\
(0.02)\end{array}$ & $\begin{array}{c}0.01 \\
(0.02)\end{array}$ & $\begin{array}{c}0.03 \\
(0.02)\end{array}$ & $\begin{array}{c}0.03 \\
(0.04)\end{array}$ & $\begin{array}{c}0.03 \\
(0.03)\end{array}$ & $\begin{array}{c}0.05 \\
(0.04)\end{array}$ \\
\hline Contractions & $\begin{array}{l}0.11^{*} \\
(0.06)\end{array}$ & $\begin{array}{l}0.11^{*} \\
(0.06)\end{array}$ & $\begin{array}{l}0.08^{*} \\
(0.05)\end{array}$ & $\begin{array}{l}0.11^{*} \\
(0.06)\end{array}$ & $\begin{array}{c}0.12^{* *} \\
(0.06)\end{array}$ & $\begin{array}{c}0.08^{* *} \\
(0.04)\end{array}$ \\
\hline Net extensive margin & $\begin{array}{c}-0.27^{* * *} \\
(0.10)\end{array}$ & $\begin{array}{c}-0.34^{* * *} \\
(0.11)\end{array}$ & $\begin{array}{c}-0.43^{* * *} \\
(0.15)\end{array}$ & $\begin{array}{c}-0.25^{* * *} \\
(0.09)\end{array}$ & $\begin{array}{c}-0.30^{* * *} \\
(0.09)\end{array}$ & $\begin{array}{c}-0.37^{* * *} \\
(0.11)\end{array}$ \\
\hline Net intensive margin & $\begin{array}{l}-0.11 \\
(0.07)\end{array}$ & $\begin{array}{l}-0.10 \\
(0.08)\end{array}$ & $\begin{array}{l}-0.05 \\
(0.05)\end{array}$ & $\begin{array}{l}-0.08 \\
(0.08)\end{array}$ & $\begin{array}{l}-0.08 \\
(0.07)\end{array}$ & $\begin{array}{l}-0.02 \\
(0.05)\end{array}$ \\
\hline Job creation & $\begin{array}{c}0.02 \\
(0.06)\end{array}$ & $\begin{array}{c}0.04 \\
(0.05)\end{array}$ & $\begin{array}{c}0.03 \\
(0.07)\end{array}$ & $\begin{array}{c}0.08 \\
(0.08)\end{array}$ & $\begin{array}{c}0.10 \\
(0.06)\end{array}$ & $\begin{array}{c}0.09 \\
(0.07)\end{array}$ \\
\hline Job destruction & $\begin{array}{c}0.40^{* * *} \\
(0.13)\end{array}$ & $\begin{array}{c}0.48^{* * *} \\
(0.14)\end{array}$ & $\begin{array}{c}0.50 * * * \\
(0.13)\end{array}$ & $\begin{array}{c}0.41^{* * *} \\
(0.13)\end{array}$ & $\begin{array}{c}0.48^{* * *} \\
(0.12)\end{array}$ & $\begin{array}{c}0.49 * * * \\
(0.11)\end{array}$ \\
\hline \multicolumn{7}{|l|}{$C B P$ data: } \\
\hline Net employment growth & $\begin{array}{c}-0.93^{* * *} \\
(0.26)\end{array}$ & $\begin{array}{c}-1.32^{* * *} \\
(0.37)\end{array}$ & $\begin{array}{c}-1.37^{* * *} \\
(0.41)\end{array}$ & $\begin{array}{c}-0.86^{* * *} \\
(0.23)\end{array}$ & $\begin{array}{c}-1.17^{* * *} \\
(0.32)\end{array}$ & $\begin{array}{c}-1.26^{* * *} \\
(0.37)\end{array}$ \\
\hline Sector $\times$ period controls & Yes & Yes & Yes & Yes & Yes & Yes \\
\hline Manf. sector controls & Yes & No & No & Yes & No & No \\
\hline Include 2008-2011 & No & No & Yes & No & No & Yes \\
\hline Observations & 958 & 958 & 958 & 958 & 958 & 958 \\
\hline
\end{tabular}

Notes: This table reports results for the effects of direct + upstream, and direct + upstream + downstream Chinese import exposure on annualized log-employment changes and job flows. All regressions include 479 industries, two subperiods (1992-1999 and either 1999-2007 or 1999-2011), and are weighted by 1992 employment. The net growth regression with CBP data is weighted by 1992 CBP employment, and is reported for the purpose of comparison with the net growth regression with NETS data. Standard errors (in parentheses) are clustered at the three-digit industry level. The coefficients are statistically significant at the $* 10 \%,{ }^{* *} 5 \%$, or $* * * 1 \%$ level.

growth (measured as the log-employment annual change), and on each of its job-flow components. Columns 1-3 use the first measure (direct+upstream) and columns 4-6 use the second measure (direct+upstream+downstream). All regressions are weighted by 1992 employment, and include different subperiod fixed effects for manufacturing industries and non-manufacturing industries. As before, standard errors are clustered at the three-digit SIC level. 
Across all specifications, the first row in Table 4 shows that an increase in any of the combined measures of Chinese import exposure is associated with net job destruction. The following four rows for the separate job flows indicate, as before, that job destruction by deaths of establishments is the main driver of this result: the import-exposure coefficient on deaths is the largest in magnitude in all specifications. The last column of Table 2, which reports the values of the estimated death share $(\hat{\delta})$ for our preferred specifications, shows that deaths explain between 71 and 80 percent of direct and upstream Chinese-induced job reallocation (from Table 4's columns 2-3), and explain between 63 and 71 percent if we consider all linkages (from Table 4's columns 5-6). Each column also shows statistically significant job destruction due to establishments' contractions, but the contractions coefficient is much smaller than the coefficient on deaths.

Comparing the magnitude of the net coefficients in the first row, note that their size is smaller when using the second combined measure of import exposure. This, however, does not mean that predicted employment losses are smaller when we consider downstream exposure, as changes in the second measure of import exposure are likely to be larger than changes in the first measure. To know whether there are larger or smaller predicted losses with the second measure, we use a formula similar to (6). Following AADHP (and our earlier discussion), we focus on the specifications that do not include the one-digit manufacturing sector dummies (columns 2, 3, 5, and 6), and report in Table 2 their predicted employment changes - the net effect as well as the contribution of each job-flow type.

For the 1992-2007 period, Chinese-induced net destruction is 0.76 million U.S. jobs when considering direct and upstream import exposures, and 0.89 million jobs if we also consider downstream import exposure. If we account for the Great Recession period, losses are slightly larger at 0.88 million jobs under the first measure, and 1 million jobs under the second measure. Hence, Chinese downstream import exposure is also a source of net job destruction for U.S. establishments. Although not reported in Table 2, we also find that for the 1992-2007 period, 21 percent of net predicted losses occur in non-manufacturing industries when we consider upstream exposure, and this share rises to 33 percent if we also consider downstream exposure (these shares are 24 and 37 percent for the 1992-2011 period).

Equations (8) and (9) show first-order upstream and downstream import penetration measures. Following Acemoglu, Carvalho, Ozdaglar, and Tahbaz-Salehi (2012), AADHP also consider higherorder ( $\mathrm{HO})$ upstream and downstream linkages - e.g., an industry is also affected by shocks to one of its buyers' buyers or sellers, or by shocks to one of its sellers' buyers or sellers, and so on. Along these lines, Table A.3 in the Appendix presents our estimation of the effects of the HO-combined 
measures of Chinese import exposure on U.S. net employment and job flows. When compared to Table 4, the results barely change in terms of signs, magnitudes, and statistical significance.

For the net-growth regressions using the CBP data in Tables 4 and A.3, the import exposure coefficients are again similar in sign and statistical significance to those obtained with NETS in the first row, but they are between 2.4 and 3.2 times larger in magnitude. In terms of net employment changes, Table A.2 shows that the CBP data predicts losses about twice as large as the NETS data. In spite of these differences, which we attribute to idiosyncratic characteristics of each dataset and remnants of NETS stickiness, CBP and NETS data never yield conflicting estimates for net employment responses. Hence, we are confident in the strength of our qualitative results.

\subsubsection{Upstream and Downstream Exposure to China's PNTR Status}

We next look at the upstream and downstream effects of China's PNTR status on U.S. net employment changes and each job-flow component. To calculate the upstream and downstream measures of China's PNTR status for industry $j$ during subperiod $\tau, U P N T R_{j \tau}$ and $D P N T R_{j \tau}$, we simply replace $\Delta I P_{g \tau}$ in equations (8) and (9) with $P N T R_{g \tau}$, which was defined in (2). As in the previous section, we simplify our analysis by using combined measures of exposure to China's PNTR status: the first measure is $P N T R_{j \tau}+U P N T R_{j \tau}$, and the second measure is $P N T R_{j \tau}+U P N T R_{j \tau}+D P N T R_{j \tau}$.

Table 5, which exactly mirrors Table 4, presents our PNTR estimation results. Similar to our previous findings, both combined measures of exposure to China's PNTR status are associated with net job destruction in the United States. Note that only the increase in job destruction by deaths significantly matters in explaining the result on net employment growth. On the other hand, the coefficients on births, expansions, and contractions are all very close to zero. As reported in panel B of Table 2, for our preferred specifications (columns 2, 3, 5, and 6), the estimated share of deaths in total PNTR-induced job reallocation, $\hat{\delta}$, ranges between 81 and 98 percent. $^{15}$

Panel B of Table 2 also reports predicted employment changes for columns 2, 3, 5, and 6 of Table 5. The net predicted losses indicate that both upstream and downstream exposure to China's PNTR status are sources of net job destruction. Up to 2007, the predicted net losses from direct and upstream exposure are about 2.5 million jobs, and about 2.8 million jobs if we consider downstream exposure as well. Up to 2011, predicted losses are respectively about 3.7 million jobs and 5.3 million jobs. As before, note from Table 2 that predicted net losses from China's PNTR exposure (in panel B) are several orders of magnitude larger - from 3 to more than 5 times larger - than losses from

\footnotetext{
${ }^{15}$ Considering higher-order upstream and downstream linkages, Table A.4 in the Appendix shows similar results to those in Table 5 .
} 
Table 5: OLS Estimation of the Effects of China's PNTR Status on U.S. Employment — with Upstream and Downstream Linkages Across Industries

\begin{tabular}{|c|c|c|c|c|c|c|}
\hline & \multicolumn{3}{|c|}{$\begin{array}{c}\text { Combined measure I } \\
(\text { direct+upstream })\end{array}$} & \multicolumn{3}{|c|}{$\begin{array}{c}\text { Combined measure II } \\
\text { (direct+upstream +downstream) }\end{array}$} \\
\hline & $(1)$ & $(2)$ & $(3)$ & $(4)$ & $(5)$ & $(6)$ \\
\hline Net employment growth & $\begin{array}{l}-0.19 \\
(0.11)\end{array}$ & $\begin{array}{c}-0.28^{* * *} \\
(0.10)\end{array}$ & $\begin{array}{c}-0.43^{* * *} \\
(0.15)\end{array}$ & $\begin{array}{l}-0.10 \\
(0.11)\end{array}$ & $\begin{array}{c}-0.21^{* *} \\
(0.10)\end{array}$ & $\begin{array}{c}-0.41^{* * *} \\
(0.13)\end{array}$ \\
\hline \multicolumn{7}{|l|}{ Job flows } \\
\hline Births & $\begin{array}{c}0.02 \\
(0.11)\end{array}$ & $\begin{array}{c}0.02 \\
(0.09)\end{array}$ & $\begin{array}{l}-0.00 \\
(0.12)\end{array}$ & $\begin{array}{c}0.03 \\
(0.10)\end{array}$ & $\begin{array}{c}0.03 \\
(0.08)\end{array}$ & $\begin{array}{l}-0.03 \\
(0.10)\end{array}$ \\
\hline Deaths & $\begin{array}{c}0.19^{* * *} \\
(0.05)\end{array}$ & $\begin{array}{c}0.27^{* * *} \\
(0.05)\end{array}$ & $\begin{array}{c}0.44^{* * *} \\
(0.10)\end{array}$ & $\begin{array}{c}0.14^{* *} \\
(0.06)\end{array}$ & $\begin{array}{l}0.22^{* * *} \\
(0.06)\end{array}$ & $\begin{array}{c}0.40^{* * *} \\
(0.10)\end{array}$ \\
\hline Expansions & $\begin{array}{l}-0.01 \\
(0.03)\end{array}$ & $\begin{array}{l}-0.01 \\
(0.03)\end{array}$ & $\begin{array}{c}0.00 \\
(0.03)\end{array}$ & $\begin{array}{l}-0.00 \\
(0.04)\end{array}$ & $\begin{array}{l}-0.01 \\
(0.03)\end{array}$ & $\begin{array}{c}0.01 \\
(0.03)\end{array}$ \\
\hline Contractions & $\begin{array}{c}0.00 \\
(0.04)\end{array}$ & $\begin{array}{c}0.01 \\
(0.03)\end{array}$ & $\begin{array}{l}-0.01 \\
(0.03)\end{array}$ & $\begin{array}{c}-0.01 \\
(0.04)\end{array}$ & $\begin{array}{c}0.01 \\
(0.03)\end{array}$ & $\begin{array}{l}-0.01 \\
(0.03)\end{array}$ \\
\hline Net extensive margin & $\begin{array}{l}-0.17 \\
(0.11)\end{array}$ & $\begin{array}{c}-0.25^{* *} \\
(0.10)\end{array}$ & $\begin{array}{c}-0.44^{* * *} \\
(0.16)\end{array}$ & $\begin{array}{c}-0.11 \\
(0.10)\end{array}$ & $\begin{array}{c}-0.20^{* *} \\
(0.09)\end{array}$ & $\begin{array}{c}-0.43^{* * *} \\
(0.13)\end{array}$ \\
\hline Net intensive margin & $\begin{array}{l}-0.01 \\
(0.05)\end{array}$ & $\begin{array}{l}-0.03 \\
(0.04)\end{array}$ & $\begin{array}{c}0.01 \\
(0.05)\end{array}$ & $\begin{array}{c}0.01 \\
(0.05)\end{array}$ & $\begin{array}{l}-0.02 \\
(0.05)\end{array}$ & $\begin{array}{c}0.03 \\
(0.05)\end{array}$ \\
\hline Job creation & $\begin{array}{c}0.01 \\
(0.10)\end{array}$ & $\begin{array}{c}0.01 \\
(0.09)\end{array}$ & $\begin{array}{c}-0.00 \\
(0.11)\end{array}$ & $\begin{array}{c}0.03 \\
(0.10)\end{array}$ & $\begin{array}{c}0.02 \\
(0.09)\end{array}$ & $\begin{array}{l}-0.02 \\
(0.10)\end{array}$ \\
\hline Job destruction & $\begin{array}{c}0.19^{* * *} \\
(0.07)\end{array}$ & $\begin{array}{c}0.28 * * * \\
(0.06)\end{array}$ & $\begin{array}{c}0.43^{* * *} \\
(0.10)\end{array}$ & $\begin{array}{c}0.13 \\
(0.08)\end{array}$ & $\begin{array}{c}0.23^{* * *} \\
(0.07)\end{array}$ & $\begin{array}{c}0.39 * * * \\
(0.10)\end{array}$ \\
\hline \multicolumn{7}{|l|}{$C B P$ data: } \\
\hline Net employment growth & $\begin{array}{c}-0.66^{* * *} \\
(0.12)\end{array}$ & $\begin{array}{c}-0.95^{* * *} \\
(0.14)\end{array}$ & $\begin{array}{c}-1.20^{* * *} \\
(0.20)\end{array}$ & $\begin{array}{c}-0.54^{* * *} \\
(0.11)\end{array}$ & $\begin{array}{c}-0.86^{* * *} \\
(0.13)\end{array}$ & $\begin{array}{c}-1.22^{* * *} \\
(0.19)\end{array}$ \\
\hline Sector $\times$ period controls & Yes & Yes & Yes & Yes & Yes & Yes \\
\hline Manf. sector controls & Yes & No & No & Yes & No & No \\
\hline Include 2008-2011 & No & No & Yes & No & No & Yes \\
\hline Observations & 958 & 958 & 958 & 958 & 958 & 958 \\
\hline
\end{tabular}

Notes: This table reports results for the effects of direct + upstream, and direct + upstream + downstream exposure to China's PNTR status on annualized log-employment changes and job flows. All regressions include 479 industries, two subperiods (1992-1999 and either 1999-2007 or 1999-2011), and are weighted by 1992 employment. The net growth regression with CBP data is weighted by 1992 CBP employment, and is reported for the purpose of comparison with the net growth regression with NETS data. Standard errors (in parentheses) are clustered at the three-digit industry level. The coefficients are statistically significant at the $* 10 \%, * * 5 \%$, or $* * * 1 \%$ level.

Chinese import exposure (in panel A).

The CBP net-growth coefficients from the last row of Table 5 are negative, highly significant, and follow the same pattern as the respective NETS coefficients, but they are much larger in magnitude. As reported in Table A.2 in the Appendix, this translates to extremely high predicted net losses ranging from 7.5 million jobs from direct and upstream PNTR exposure up to 2007, to 
13.2 million jobs from all exposure types up to 2011. Of course, these predicted losses must be taken with extreme caution.

\section{Local Labor Markets Analysis}

The influential work of Autor, Dorn, and Hanson (2013) showed that, due to aggregate demand effects, import competition from China has employment effects in local labor markets that go far deeper than the impact in directly-exposed sectors. For example, displaced workers from an exposed industry in Pittsburgh will have less income, which then drives these fired workers to spend less on other goods and services such as haircuts, which then depresses the incomes of barbershops and hair salons, and so forth. AADHP extend this framework to try to capture job reallocation from exposed sectors to non-exposed sectors.

Here we expand AADHP's local labor markets analysis along three dimensions. First, by looking at each of the components of job flows rather than only at net employment changes, we are in a better position to capture evidence of job reallocation across exposed and non-exposed sectors. Second, we also look at the local labor market employment effects of U.S. exposure to China's PNTR status, which helps to establish the generality of our results. And third, we add a "Bartik shock" as a regressor in our specifications, which allows us to study whether the employment responses we observe due to the China shock are distinctive, or if they are similar to responses to a generic negative shock that affects the demand for U.S. labor.

\subsection{Measures of the China Shock at the Commuting-Zone Level and the Bartik Shock}

The analysis is based on the 722 U.S. commuting zones of Autor, Dorn, and Hanson (2013) and AADHP. The first step is to obtain the measure of Chinese import exposure at the commuting zone level. This variable is defined as a weighted average of the annual changes in industry-level import penetration, with the weights - the initial employment share of each industry in total commutingzone employment - accounting for regional specialization patterns. Hence, the annual change in import penetration in commuting zone $i$ during subperiod $\tau, \Delta I P_{i \tau}^{C Z}$, is given by

$$
\Delta I P_{i \tau}^{C Z}=\sum_{j}\left(\frac{L_{i j t_{\tau, \text { start }}}}{L_{i t_{\tau, \text { start }}}}\right) \Delta I P_{j \tau},
$$

where $L_{i j t_{\tau, \text { start }}}$ is the level of employment in commuting zone $i$ in industry $j$ at $t_{\tau, \text { start }}$ (the initial year of subperiod $\tau), L_{i t_{\tau, \text { start }}}=\sum_{j^{\prime}} L_{i j^{\prime} t_{\tau, \text { start }}}$ is total employment in commuting zone $i$ at $t_{\tau, \text { start }}$, and $\Delta I P_{j \tau}$ is the annual change in import penetration in industry $j$ during subperiod $\tau$ as defined in (1). 
Analogously, the measure of exposure to China's PNTR status for commuting zone $i$ during subperiod $\tau, P N T R_{i \tau}^{C Z}$, is given by

$$
P N T R_{i \tau}^{C Z}=\sum_{j}\left(\frac{L_{i j t_{\tau, \text { start }}}}{L_{i t_{\tau, \mathrm{start}}}}\right) P N T R_{j \tau},
$$

where $P N T R_{j \tau}$, which is defined in (2), is zero if $\tau=1$ and equals the annualized NTR gap in industry $j$ if $\tau=2$. As before, $\tau \in\{1,2\}$, with period 1 corresponding to 1992-1999, and period 2 corresponding to either 1999-2007 or 1999-2011.

Our industry-level analysis in section 5 obtained a very concrete result regarding the impact of the China shock on U.S. employment and job flows: net job destruction driven mainly by deaths of establishments. An important concern is whether this result is particular to the China shock, or if it is the typical way the U.S. labor market responds to a more general adverse shock affecting the U.S. demand for labor. A key advantage of the local labor markets approach is that we can explore the particularity of the China shock by introducing a Bartik shock at the commuting zone level. ${ }^{16}$

Following Autor, Dorn, Hanson, and Majlesi (2016), the Bartik measure for commuting zone $i$ during subperiod $\tau, \mathbb{B}_{i \tau}$, is defined as

$$
\mathbb{B}_{i \tau} \equiv \sum_{j}\left(\frac{L_{i j t_{\tau, \text { start }}}}{L_{i t_{\tau, \text { start }}}}\right) \frac{\Delta L_{j \tau}^{-i}}{L_{j t_{\tau, \text { start }}}^{-i}},
$$

where $\Delta L_{j \tau}^{-i}$ denotes the annual change in industry $j$ 's employment during subperiod $\tau$ across all U.S. commuting zones with the exception of commuting zone $i$. The Bartik shock indicates the predicted change in employment in commuting zone $i$ as a result of national industry-level employment changes, using as weights the initial share of each industry in the commuting zone's employment to account for regional specialization patterns. ${ }^{17}$

\subsection{Specifications}

Following AADHP's approach, each of the 479 industries is classified into one of three sectors: exposed, nonexposed tradable, and nonexposed nontradable. ${ }^{18}$ We use $k \in\{1,2,3\}$ to indicate

\footnotetext{
${ }^{16}$ We thank Gordon Hanson for raising this point and suggesting the construction of the Bartik measure.

${ }^{17}$ The Bartik measure captures all factors that affect the U.S. demand for domestic labor, including the China shock. Fortunately, the correlations between the Bartik variable and our measures of Chinese exposure are low, which allow us to keep a high degree of precision in our estimates when we include both types of shocks.

${ }^{18}$ AADHP classify an industry as exposed if predicted import exposure from the first-stage regression increased by more than 2 percentage points between 1991 and 2011, or if the predicted higher-order upstream exposure measure increased by more than 4 percentage points during the same period. From 1992 to 2011 and using our NETS data, the employment share of the exposed sector declined from 19 percent to 13 percent, the share of the nonexposed tradable sector declined from 6 percent to 4 percent, and the share of the nonexposed nontradable sector increased from 75 to 83 percent. With the CBP data, the shares respectively changed from 20 to 13 percent, 7 to 4 percent, and 73 to 83 percent.
} 
sector type, so that 1 identifies the exposed sector, 2 identifies the nonexposed tradable sector, and 3 identifies the nonexposed nontradable sector. After classifying each industry in each commuting zone, we aggregate the NETS job flows data across the three sectors and the 722 commuting zones. This creates a panel with 4,332 observations: 722 commuting zones, three sectors, and two periods.

The dependent variable in the local labor market analysis is based on the employment-topopulation ratio. Here we define the annual change in the employment-to-population ratio in sector $k$ in commuting zone $i$ in subperiod $\tau$ as

$$
\ell_{i k \tau}=\frac{\Delta L_{i k \tau}}{\bar{P}_{i \tau}},
$$

where for each commuting zone $i$ during subperiod $\tau, \Delta L_{i k \tau}$ is the annual employment change in sector $k$, and $\bar{P}_{i \tau}$ is the mid-point working-age population $\left(i . e ., \bar{P}_{i \tau}=\left(P_{i t_{\tau, \text { end }}}+P_{i t_{\tau, \text { start }}}\right) / 2\right)$. We obtain the working-age population for each commuting zone $i$ and each year $t, P_{i t}$, from AADHP, who construct it from Census population estimates. ${ }^{19}$

The specification to estimate the net impact of local exposure to the China shock on employmentto-population ratios for different sectors is

$$
\ell_{i k \tau}=\alpha_{k \tau}+\sum_{k} \beta_{k}\left[S_{i \tau}^{C Z} \times \mathbb{1}_{k}\right]+\sum_{k} \gamma_{k}\left[\mathbb{B}_{i \tau} \times \mathbb{1}_{k}\right]+\eta_{k} Z_{i k \tau}+\varepsilon_{i k \tau}
$$

where for commuting zone $i$ and sector $k \in\{1,2,3\}$ during subperiod $\tau, S_{i \tau}^{C Z}$ is the China shock variable, measured as either $\Delta I P_{i \tau}^{C Z}$ in (10) or $P N T R_{i \tau}^{C Z}$ in (11), and $\mathbb{B}_{i \tau}$ is the Bartik shock from (12). In addition, $\mathbb{1}_{k}$ is a sectoral dummy, $Z_{i k \tau}$ is a vector of commuting zone $i$-sector $k$ controls, $\alpha_{k \tau}$ indicates a sector-time fixed effect, and $\varepsilon_{i k \tau}$ is the error term. Note that the specification not only allows for different sectoral net responses to the China shock (accounted for by $\beta_{1}, \beta_{2}$, and $\beta_{3}$ ), but also allows for different sectoral responses to the Bartik shock (accounted for by $\gamma_{1}, \gamma_{2}$, and $\left.\gamma_{3}\right)$.

With a slight notational abuse, we can now split the annual change in the employment-topopulation ratio into its job-flow components as

$$
\ell_{i k \tau} \equiv b_{i k \tau}-d_{i k \tau}+e_{i k \tau}-c_{i k \tau}
$$

where $b_{i k \tau}$ denotes the contribution of births to the change in the employment-to-population ratio in sector $k$ in commuting zone $i$, and the same for deaths $\left(d_{i k \tau}\right)$, expansions $\left(e_{i k \tau}\right)$, and contractions $\left(c_{i k \tau}\right)$. We calculate $b_{i k \tau}$ as

$$
b_{i k \tau}=\lambda_{\tau}\left(\frac{B_{i k \tau}}{\bar{P}_{i \tau}}\right)
$$

\footnotetext{
${ }^{19}$ The measure in (13) is slightly different from the measure used by AADHP, which is given by $\Delta \mathbb{E}_{i k \tau}$, where $\mathbb{E}_{i k t}=L_{i k t} / P_{i t}$. We use the alternative measure to be able to separate each of the job-flow components.
} 
where $B_{i k \tau}$ is the employment change due to births of establishments in sector $k$ of commuting zone $i$ during subperiod $\tau$. Analogous expressions follow for $d_{i k \tau}, e_{i k \tau}$, and $c_{i k \tau}$.

Thus, our specification to estimate the impact of local exposure to the China shock on job flow

$$
\begin{aligned}
& F_{i k \tau} \in\left\{b_{i k \tau}, d_{i k \tau}, e_{i k \tau}, c_{i k \tau}, b_{i k \tau}-d_{i k \tau}, e_{i k \tau}-c_{i k \tau}, b_{i k \tau}+e_{i k \tau}, d_{i k \tau}+c_{i k \tau}\right\} \text { is } \\
& F_{i k \tau}=\alpha_{k \tau}^{F}+\sum_{k} \beta_{k}^{F}\left[S_{i t}^{C Z} \times \mathbb{1}_{k}\right]+\sum_{k} \gamma_{k}^{F}\left[\mathbb{B}_{i \tau} \times \mathbb{1}_{k}\right]+\eta_{k}^{F} Z_{i k \tau}+\varepsilon_{i k \tau}^{F} .
\end{aligned}
$$

As before, there is a perfect linear relationship between the gross coefficients spanned from (15) and the net coefficients from (14), so it is always true that

$$
\begin{aligned}
& \beta_{k} \equiv \beta_{k}^{b}-\beta_{k}^{d}+\beta_{k}^{e}-\beta_{k}^{c} \equiv \beta_{k}^{b-d}+\beta_{k}^{e-c} \equiv \beta_{k}^{b+e}-\beta_{k}^{d+c} \\
& \gamma_{k} \equiv \gamma_{k}^{b}-\gamma_{k}^{d}+\gamma_{k}^{e}-\gamma_{k}^{c} \equiv \gamma_{k}^{b-d}+\gamma_{k}^{e-c} \equiv \gamma_{k}^{b+e}-\gamma_{k}^{d+c}
\end{aligned}
$$

for $k \in\{1,2,3\}$.

\subsection{Local Labor Market Effects of Chinese Import Exposure}

Using the local measure of Chinese import exposure $\left(\Delta I P_{i \tau}^{C Z}\right)$ as the China shock, Table 6 shows the IV estimation of (14) and (15) for the 1992-2007 period. ${ }^{20}$ In contrast to Tables 1-5, where each coefficient was the estimate of $\beta$ or $\beta^{F}$ from a single regression, in Table 6 each full row gives the estimates from a single regression. For example, the first row yields $\hat{\beta}_{1}, \hat{\beta}_{2}, \hat{\beta}_{3}, \hat{\gamma}_{1}, \hat{\gamma}_{2}$, and $\hat{\gamma}_{3}$ from the estimation of (14) with NETS data.

In addition to sector-time fixed effects, we follow AADHP and include as controls (i) the commuting zone's manufacturing share (at the beginning of each period) interacted with sector dummies, and (ii) regional Census division dummies interacted with sector dummies. All regressions include 4,332 observations and are weighted by total population in 1992, with standard errors clustered at the commuting-zone level.

The first coefficient in the first row of Table 6 shows a strong and highly significant negative response of the employment-to-population ratio in the exposed sector to an increase in local Chinese import exposure. As in the industry-level analysis, the job-flow coefficients in column 1 show that the main driving factor of the decline in the exposed sector's employment-to-population ratio is an increase in job destruction due to establishments' deaths. Based on our death-share measure $(\hat{\delta})$ defined in (5) and reported in the last column of Table 2, deaths account for 55 percent of total Chinese-induced job reallocation in the exposed sector during the 1992-2007 period.

\footnotetext{
${ }^{20}$ Following AADHP, the instrument for $\Delta I P_{i \tau}^{C Z}$ is $\Delta I P_{i \tau}^{* C Z}=\sum_{j}\left(\frac{L_{i j 88}}{L_{i 88}}\right) \Delta I P_{j \tau}^{*}$. They use employment weights from 1988 in the instrument to avoid covariance with the dependent variable.
} 
Table 6: IV Estimation of the Effects of Chinese Import Exposure on U.S. Commuting Zones by Sectoral Employment (1992-2007)

\begin{tabular}{|c|c|c|c|c|c|c|}
\hline & \multicolumn{3}{|c|}{ Chinese Import Exposure } & \multicolumn{3}{|c|}{ Bartik Shock } \\
\hline & Exposed & $\begin{array}{c}\text { Nonexposed } \\
\text { tradable }\end{array}$ & $\begin{array}{l}\text { Nonexposed } \\
\text { nontradable }\end{array}$ & Exposed & $\begin{array}{c}\text { Nonexposed } \\
\text { tradable }\end{array}$ & $\begin{array}{l}\text { Nonexposed } \\
\text { nontradable }\end{array}$ \\
\hline$\Delta$ (Employment/Population) & $\begin{array}{c}-1.10^{* * *} \\
(0.21)\end{array}$ & $\begin{array}{c}0.10 \\
(0.12)\end{array}$ & $\begin{array}{c}1.16^{* * *} \\
(0.44)\end{array}$ & $\begin{array}{c}0.19^{* * *} \\
(0.04)\end{array}$ & $\begin{array}{l}-0.01 \\
(0.02)\end{array}$ & $\begin{array}{c}0.79^{* * *} \\
(0.11)\end{array}$ \\
\hline \multicolumn{7}{|l|}{ Job flows } \\
\hline Births & $\begin{array}{c}0.30^{* * *} \\
(0.11)\end{array}$ & $\begin{array}{l}-0.13^{*} \\
(0.07)\end{array}$ & $\begin{array}{c}1.95^{* * *} \\
(0.56)\end{array}$ & $\begin{array}{c}0.23^{* * *} \\
(0.03)\end{array}$ & $\begin{array}{c}0.03^{* * *} * \\
(0.01)\end{array}$ & $\begin{array}{c}1.40^{* * *} \\
(0.12)\end{array}$ \\
\hline Deaths & $\begin{array}{c}1.12^{* * *} \\
(0.17)\end{array}$ & $\begin{array}{l}-0.10 \\
(0.07)\end{array}$ & $\begin{array}{l}1.28^{* *} \\
(0.50)\end{array}$ & $\begin{array}{c}0.19^{* * * *} \\
(0.03)\end{array}$ & $\begin{array}{c}0.05^{* * *} \\
(0.01)\end{array}$ & $\begin{array}{c}0.85^{* * *} \\
(0.08)\end{array}$ \\
\hline Expansions & $\begin{array}{c}0.17 \\
(0.11)\end{array}$ & $\begin{array}{l}-0.11^{*} \\
(0.06)\end{array}$ & $\begin{array}{c}0.50 \\
(0.31)\end{array}$ & $\begin{array}{c}0.15^{* * *} \\
(0.02)\end{array}$ & $\begin{array}{c}0.03^{* * *} \\
(0.01)\end{array}$ & $\begin{array}{c}0.44^{* * *} \\
(0.05)\end{array}$ \\
\hline Contractions & $\begin{array}{c}0.45^{* * *} \\
(0.10)\end{array}$ & $\begin{array}{c}-0.24^{* * *} \\
(0.09)\end{array}$ & $\begin{array}{c}0.02 \\
(0.23)\end{array}$ & $\begin{array}{l}-0.00 \\
(0.01)\end{array}$ & $\begin{array}{l}0.02^{* *} \\
(0.01)\end{array}$ & $\begin{array}{c}0.20^{* * *} \\
(0.05)\end{array}$ \\
\hline Net extensive margin & $\begin{array}{c}-0.82^{* * *} \\
(0.15)\end{array}$ & $\begin{array}{l}-0.03 \\
(0.07)\end{array}$ & $\begin{array}{l}0.67^{*} \\
(0.40)\end{array}$ & $\begin{array}{c}0.04^{*} \\
(0.02)\end{array}$ & $\begin{array}{l}-0.02 * \\
(0.01)\end{array}$ & $\begin{array}{c}0.56^{* * *} \\
(0.09)\end{array}$ \\
\hline Net intensive margin & $\begin{array}{c}-0.28^{* *} \\
(0.12)\end{array}$ & $\begin{array}{l}0.13^{*} \\
(0.07)\end{array}$ & $\begin{array}{c}0.48^{* * *} \\
(0.16)\end{array}$ & $\begin{array}{c}0.15^{* * *} \\
(0.02)\end{array}$ & $\begin{array}{c}0.01 \\
(0.01)\end{array}$ & $\begin{array}{c}0.24^{* * *} \\
(0.04)\end{array}$ \\
\hline Job creation & $\begin{array}{c}0.47^{* *} \\
(0.20)\end{array}$ & $\begin{array}{c}-0.23^{* *} \\
(0.11)\end{array}$ & $\begin{array}{c}2.45^{* * *} \\
(0.79)\end{array}$ & $\begin{array}{c}0.37^{* * *} \\
(0.04)\end{array}$ & $\begin{array}{c}0.06^{* * *} \\
(0.02)\end{array}$ & $\begin{array}{c}1.84^{* * *} \\
(0.15)\end{array}$ \\
\hline Job destruction & $\begin{array}{c}1.58^{* * *} \\
(0.25)\end{array}$ & $\begin{array}{c}-0.34^{* *} \\
(0.14)\end{array}$ & $\begin{array}{l}1.30^{*} \\
(0.70)\end{array}$ & $\begin{array}{c}0.18^{* * *} \\
(0.04)\end{array}$ & $\begin{array}{c}0.07 * * * \\
(0.02)\end{array}$ & $\begin{array}{c}1.05^{* * *} \\
(0.11)\end{array}$ \\
\hline \multicolumn{7}{|l|}{$C B P$ data: } \\
\hline$\overline{\Delta(\text { Employment/Population })}$ & $\begin{array}{c}-1.24^{* * *} \\
(0.25)\end{array}$ & $\begin{array}{l}-0.10 \\
(0.10)\end{array}$ & $\begin{array}{l}1.39^{* *} \\
(0.67)\end{array}$ & $\begin{array}{c}0.16^{* * *} \\
(0.02)\end{array}$ & $\begin{array}{l}0.02^{*} \\
(0.01)\end{array}$ & $\begin{array}{c}0.47^{* * *} \\
(0.08)\end{array}$ \\
\hline
\end{tabular}

Notes: Using subperiods 1992-1999, 1999-2007, and import exposure as the China shock, this table reports $\hat{\beta}_{k}, \hat{\gamma}_{k}, \hat{\beta}_{k}^{F}$, and $\hat{\gamma}_{k}^{F}$, for $k \in\{1$ (exposed), 2(nonexposed tradable),3(nonexposed nontradable)\}, from the estimation of specifications (14) and (15). All regressions include 4,332 observations (722 commuting zones, three sectors, and two subperiods) and the following controls: sectortime fixed effects, the commuting zone's manufacturing share (at the beginning of each period) interacted with sector dummies, and regional Census division dummies interacted with sector dummies. Regressions are weighted by 1992 commuting-zone population. The net regression with CBP data is reported for the purpose of comparison with the net regression with NETS data. Standard errors (in parentheses) are clustered at the commuting-zone level. The coefficients are statistically significant at the $* 10 \%, * * 5 \%$, or *** $1 \%$ level. 
Although job destruction by deaths is the most important gross margin of adjustment for the exposed sector, column 1 shows that an increase in job creation by births and an increase in job destruction by contractions also play a statistically significant role in the net dynamics of the employment-to-population ratio. In the end, the exposed sector shows gross job reallocation that is 1.85 times larger than the observed net effect, which highlights the importance of looking at job flows rather than at net employment changes (which miss substantial labor market activity).

Although the births coefficient for the exposed sector is only about a fourth of the size of the deaths coefficient (and about two thirds of the size of the contractions coefficient), it is still relatively large and highly significant. Given that the coefficient on births was negative or very close to zero (always non-significant) in our industry-level analysis in sections 5 and 5.2 , the positive and significant births coefficient in the first column of Table 6 points toward reallocation effects within the exposed sector and possibly from the nonexposed sectors. This indicates that even if the exposed sector is facing a mostly adverse scenario due to Chinese competition, there are still some entrepreneurs that see the shock as an opportunity to try to capture market shares from dying and contracting firms.

The Bartik shock coefficients for the exposed sector in column 4 show fundamentally different effects on net and gross job flows from those observed in column 1. A positive Bartik shock expands net employment in the exposed sector driven by both births and expansions, and in spite of a statistically significant increase in deaths. This seems to be part of a healthy process of competition by which a positive shock stimulates entry and the expansion of most productive establishments, while destroying the least productive ones. In this case, deaths only account for 33 percent of total job reallocation, while births and expansions account for 40 and 26 percent of job reallocation, respectively. Analogously, an adverse Bartik shock causes net job destruction due to declines in births and expansions, and in spite of a decline in deaths. Thus, when compared to the effects of import exposure from China on the exposed sector, for an adverse Bartik shock deaths are not as important for gross job flows, and also have opposite implications for job reallocation.

Further interesting results from Table 6 arise from the nonexposed sectors. AADHP carefully discuss the China shock implications for job reallocation and aggregate demand effects for the nonexposed sectors, but they are not able to find statistically significant evidence of any of them. This is not surprising, given that aggregate demand effects and job reallocation from the exposed sector have opposite impacts on the employment-to-population ratios in the nonexposed sectors. Both of them may be important, but if they cancel out we will not be able to detect effects by looking only at the net change. Fortunately, by being able to decompose net employment changes 
into their job-flow components, we are in a better position to capture and detect these separate effects.

For the nonexposed tradable sector in column 2, note that although we do not observe a statistically significant net effect coefficient from local exposure to Chinese imports, there are statistically significant job-flow responses for births, expansions, and contractions (total job reallocation is 5.8 times larger than net job reallocation). Even more interesting, this sector shows declines in the rates of creation by births and expansions, which point toward negative aggregate demand effects, but also features an even larger decline in the rates of job destruction by contraction. With nonexposed tradable firms hiring and being born at a lower pace, but dying and contracting at an even lower rate, the net result (though not significant) is a small increase in the sector's employmentto-population ratio. $^{21}$

Column 5 shows that the net impact of a positive Bartik shock on the employment-to-population ratio in the nonexposed tradable sector is close to zero. However, the job flows regressions show statistically significant job creation by both births and expansions, and statistically significant job destruction by deaths and contractions. Analogously, an adverse Bartik shock reduces the rate of job creation along its two margins (births and expansions), but also reduces the rate of job destruction along its two margins (deaths and contractions), rendering an almost zero net effect. Thus, for employment in the nonexposed tradable sector, an adverse Bartik shock and a local increase in Chinese import exposure have very similar effects. Given that this sector is not an evident reallocation destination of released workers from the exposed sector, it makes sense that the China shock is seen as a general Bartik shock from the perspective of nonexposed-tradable establishments.

For the nonexposed nontradable sector, which on average accounts for about 78 percent of employment per year, column 3 shows a large and statistically significant increase in the employmentto-population ratio after a local increase in Chinese import exposure. This is strong evidence of job reallocation from the exposed sector. The job flows regressions show that the positive net effect is a consequence of a very large and statistically significant increase in the rate of job creation by births, which more than makes up for a large and significant increase in the rate of job destruction by deaths (births account for 52 percent of the sector's job reallocation, but it also helps that there is a statistically significant net expansion at the intensive margin). Therefore, as the exposed sector

\footnotetext{
${ }^{21}$ An interesting interpretation of this result, pointed out by our discussant Penny Goldberg, is whether the China shock is causing U.S. establishments - even if located in nonexposed sectors - to engage in a "race to the bottom" by which workers are willing to accept worse employment conditions due to the fear of losing their jobs in an adverse market with few hires and births. Facing less resistance from workers, establishments also have less incentives to fire them; e.g., instead of firing expensive workers to hire cheaper ones, establishments simply cut wages or benefits.
} 
sheds jobs (mainly through deaths), some of the released workers create new establishments in the nonexposed sector; there may even be previously exposed-sector establishments that are reborn in a different nonexposed industry. This reallocation mechanism is sufficiently strong to dominate the job destruction by deaths, which is likely driven by aggregate demand effects.

Column 6 indicates that a positive Bartik shock significantly increases the rates of job creation and destruction across all margins in the nonexposed nontradable sector, but job creation (especially by births) strongly dominates, resulting in a large and highly significant positive net effect. This is very similar to the response of the exposed sector to the positive Bartik shock, and resembles a healthy process of creative destruction and market share reallocations toward more productive firms. On the other hand, an adverse Bartik shock reduces the rates of job destruction along its two margins, but reduces even more the rates of job creation along its two margins. This is different from what we observe in the sector after an increase in local Chinese import exposure, which is expected given that the nontradable sector is the main reallocation destination of released workers from the exposed sector due to the China shock.

Panel A in Table 2 shows Chinese-induced predicted employment changes from the specifications in Table 6. Given that the dependent variable is now based on the employment-to-population ratio, we can no longer use a formula analogous to (6). Instead, the predicted net employment change in sector $k$ from the change in local import penetration during the 1992-2007 period is given by

$$
\text { Predicted employment change in sector } k(I P)=\sum_{i} \hat{\beta}_{k}\left(I P_{i 07}^{C Z}-I P_{i 92}^{C Z}\right) \rho P_{i 07} \text {, }
$$

where $\hat{\beta}_{k}$ is the coefficient for sector $k$ from the employment-to-population ratio regression in the first row of Table 6, $I P_{i 07}^{C Z}-I P_{i 92}^{C Z}$ is the change in import exposure for commuting zone $i$ from 1992 to $2007, P_{i 07}$ is the working-age population in commuting zone $i$ in 2007 , and $\rho=0.66$ is the partial $R$-squared from the first-stage regression of the specification in column 2 of Table $1 .{ }^{22}$

For the 1992-2007 period, Chinese-induced net predicted losses are about 2.1 million jobs in the exposed sector, but there are also significant net predicted gains of 2.2 million jobs in the nonexposed nontradable sector. Hence, in terms of net employment changes, our local labor market results indicate an almost neutral effect of Chinese import exposure. The nonexposed nontradable sector creates 3.8 million jobs from births of establishments - a sign of job reallocation from the exposed sector (gross job destruction in the exposed sector is about 3 million jobs) - but this effect is diluted by large job losses from deaths (about 2.5 million jobs). For the nonexposed tradable

\footnotetext{
${ }^{22}$ We follow AADHP in using the same $\rho$ to calculate predicted employment changes from all import-exposure specifications using the same dataset. As mentioned in section 5.1.1, $\rho$ equals 0.66 when using NETS data, and 0.60 when using CBP data.
} 
sector, the Chinese-induced job losses due to the reductions in the rates of births and expansions (about 0.47 million jobs) are exactly matched by an increase in employment due to the decline in the rate of contractions.

When using the CBP data, the net coefficients for Chinese import exposure in the last row of Table 6 are remarkably close to those obtained with the NETS data in the first row, showing also statistically significant net job destruction in the exposed sector, but also statistically significant job creation is the nonexposed nontradable sector. Regarding predicted employment changes, Table A.2 shows that the NETS and CBP data yield very similar net job losses in the exposed sector and net job gains in the nonexposed nontradable sector. The strong similarity between the NETS and CBP local labor markets results is striking, considering that the industry-level analysis consistently predicted considerably smaller net losses with NETS.

Finally, Table A.5 in the Appendix shows the estimation results for the 1992-2011 period. The results are very similar to those in Table 6 in terms of signs, magnitudes, and signficance. Thus, our qualitative results remain when we include the Great Recession period. In terms of predicted employment changes, Table 2 shows more net losses in the exposed sector during 1992-2011 (2.5 million jobs in 1992-2011 vs. 2.1 million jobs in 1992-2007), but a similar amount of net job gains in the nonexposed nontradable sector (2.2 million jobs during both periods).

\subsection{Local Labor Market Effects of China's PNTR Status}

Table 7 mirrors Table 6, but uses instead local exposure to China's PNTR status, $P N T R_{i \tau}$, as our China shock variable. Keeping up with this paper's main conclusion, column 1 shows that local exposure to China's PNTR status is associated with net job destruction in the exposed sector, with deaths of establishments being the main driver of this result; according to the corresponding value of $\hat{\delta}$ from Table 2, deaths account for 67 percent of total job reallocation in that sector. Job destruction by contractions also plays an important role, but not as prominent as deaths. As with import exposure, these employment responses are fundamentally different from those of an adverse Bartik shock, which highlights the uniqueness of the China shock.

In column 2, the nonexposed tradable sector also shows deaths-driven net job destruction due to local exposure to China's PNTR status. This is the only sector for which we obtain different qualitative results to those obtained in Table 6, which indicated reductions in both the rates of job creation and destruction due to Chinese import exposure. We do not have a precise explanation for this difference, other than our three-sector classification is the same as AADHP, which is based on the import exposure measure (see footnote 18). Thus, even though a sector may be classified as "nonexposed tradable" under the import-exposure criteria, it may well be classified as "exposed" 
Table 7: OLS Estimation of the Effects of China's PNTR Status on U.S. Commuting Zones by Sectoral Employment (1992-2007)

\begin{tabular}{|c|c|c|c|c|c|c|}
\hline & \multicolumn{3}{|c|}{ PNTR Status } & \multicolumn{3}{|c|}{ Bartik Shock } \\
\hline & Exposed & $\begin{array}{c}\text { Nonexposed } \\
\text { tradable }\end{array}$ & $\begin{array}{l}\text { Nonexposed } \\
\text { nontradable }\end{array}$ & Exposed & $\begin{array}{c}\text { Nonexposed } \\
\text { tradable }\end{array}$ & $\begin{array}{l}\text { Nonexposed } \\
\text { nontradable }\end{array}$ \\
\hline$\Delta$ (Employment/Population) & $\begin{array}{c}-0.44^{* * *} \\
(0.06)\end{array}$ & $\begin{array}{l}-0.07^{*} \\
(0.04)\end{array}$ & $\begin{array}{c}0.31^{* *} \\
(0.13)\end{array}$ & $\begin{array}{c}0.15^{* * *} \\
(0.04)\end{array}$ & $\begin{array}{l}-0.02 \\
(0.02)\end{array}$ & $\begin{array}{c}0.82^{* * *} \\
(0.10)\end{array}$ \\
\hline \multicolumn{7}{|l|}{ Job flows } \\
\hline Births & $\begin{array}{l}-0.02 \\
(0.03)\end{array}$ & $\begin{array}{c}0.00 \\
(0.01)\end{array}$ & $\begin{array}{c}0.47^{* * *} \\
(0.12)\end{array}$ & $\begin{array}{c}0.22^{* * *} \\
(0.03)\end{array}$ & $\begin{array}{c}0.03^{* * *} \\
(0.01)\end{array}$ & $\begin{array}{c}1.45^{* * *} \\
(0.12)\end{array}$ \\
\hline Deaths & $\begin{array}{c}0.33^{* * *} \\
(0.04)\end{array}$ & $\begin{array}{c}0.06^{* * *} \\
(0.02)\end{array}$ & $\begin{array}{c}0.27^{* *} \\
(0.12)\end{array}$ & $\begin{array}{c}0.22^{* * *} \\
(0.03)\end{array}$ & $\begin{array}{c}0.06^{* * *} \\
(0.01)\end{array}$ & $\begin{array}{c}0.87^{* * *} \\
(0.08)\end{array}$ \\
\hline Expansions & $\begin{array}{c}0.02 \\
(0.03)\end{array}$ & $\begin{array}{c}0.00 \\
(0.02)\end{array}$ & $\begin{array}{c}0.14^{* * * *} \\
(0.05)\end{array}$ & $\begin{array}{c}0.15^{* * *} \\
(0.02)\end{array}$ & $\begin{array}{l}0.03^{* *} \\
(0.01)\end{array}$ & $\begin{array}{c}0.45^{* * *} \\
(0.05)\end{array}$ \\
\hline Contractions & $\begin{array}{c}0.12^{* * *} \\
(0.03)\end{array}$ & $\begin{array}{c}0.02 \\
(0.02)\end{array}$ & $\begin{array}{c}0.02 \\
(0.04)\end{array}$ & $\begin{array}{c}0.01 \\
(0.01)\end{array}$ & $\begin{array}{c}0.02 * * \\
(0.01)\end{array}$ & $\begin{array}{c}0.20^{* * *} \\
(0.05)\end{array}$ \\
\hline Net extensive margin & $\begin{array}{c}-0.34^{* * *} \\
(0.04)\end{array}$ & $\begin{array}{c}-0.06^{* * *} \\
(0.02)\end{array}$ & $\begin{array}{l}0.20^{*} \\
(0.11)\end{array}$ & $\begin{array}{c}0.00 \\
(0.02)\end{array}$ & $\begin{array}{c}-0.03^{* *} \\
(0.01)\end{array}$ & $\begin{array}{c}0.58^{* * *} \\
(0.09)\end{array}$ \\
\hline Net intensive margin & $\begin{array}{c}-0.10^{* *} \\
(0.04)\end{array}$ & $\begin{array}{l}-0.02 \\
(0.03)\end{array}$ & $\begin{array}{c}0.11 * * \\
(0.04)\end{array}$ & $\begin{array}{c}0.14^{* * *} \\
(0.02)\end{array}$ & $\begin{array}{c}0.01 \\
(0.01)\end{array}$ & $\begin{array}{c}0.25^{* * *} \\
(0.04)\end{array}$ \\
\hline Job creation & $\begin{array}{c}0.00 \\
(0.05)\end{array}$ & $\begin{array}{c}0.00 \\
(0.02)\end{array}$ & $\begin{array}{c}0.61^{* * *} \\
(0.16)\end{array}$ & $\begin{array}{c}0.37^{* * *} \\
(0.04)\end{array}$ & $\begin{array}{c}0.06^{* * *} \\
(0.02)\end{array}$ & $\begin{array}{c}1.90^{* * *} \\
(0.15)\end{array}$ \\
\hline Job destruction & $\begin{array}{c}0.44^{* * *} \\
(0.06)\end{array}$ & $\begin{array}{c}0.08^{* * *} \\
(0.03)\end{array}$ & $\begin{array}{l}0.29^{*} \\
(0.15)\end{array}$ & $\begin{array}{c}0.22^{* * *} \\
(0.04)\end{array}$ & $\begin{array}{c}0.08^{* * *} \\
(0.02)\end{array}$ & $\begin{array}{c}1.07^{* * * *} \\
(0.11)\end{array}$ \\
\hline \multicolumn{7}{|l|}{ CBP data: } \\
\hline$\Delta$ (Employment/Population) & $\begin{array}{c}-0.34^{* * *} \\
(0.04)\end{array}$ & $\begin{array}{c}-0.12^{* * *} \\
(0.02)\end{array}$ & $\begin{array}{c}0.21 \\
(0.19)\end{array}$ & $\begin{array}{c}0.16^{* * *} \\
(0.02)\end{array}$ & $\begin{array}{c}0.02 \\
(0.01)\end{array}$ & $\begin{array}{c}0.46^{* * *} \\
(0.08)\end{array}$ \\
\hline
\end{tabular}

Notes: Using subperiods 1992-1999, 1999-2007, and PNTR status as the China shock, this table reports $\hat{\beta}_{k}, \hat{\gamma}_{k}, \hat{\beta}_{k}^{F}$, and $\hat{\gamma}_{k}^{F}$, for $k \in\{1$ (exposed), 2(nonexposed tradable), 3(nonexposed nontradable)\}, from the estimation of specifications (14) and (15). All regressions include 4,332 observations (722 commuting zones, three sectors, and two subperiods) and the following controls: sectortime fixed effects, the commuting zone's manufacturing share (at the beginning of each period) interacted with sector dummies, and regional Census division dummies interacted with sector dummies. Regressions are weighted by 1992 commuting-zone population. The net regression with CBP data is reported for the purpose of comparison with the net regression with NETS data. Standard errors (in parentheses) are clustered at the commuting-zone level. The coefficients are statistically significant at the $* 10 \%, * * 5 \%$, or *** $1 \%$ level. 
under a PNTR-classification criteria. Given that the nonexposed tradable sector is very small (accounting on average for 5 percent of employment per year), we do not further explore this issue.

As with the import-exposure measure, column 3 shows net job creation in the nonexposed nontradable sector due to local exposure to China's PNTR status. As before, this result is mostly driven by births, which account for 54 percent of job reallocation in the sector. Although there is statistically significant job destruction by deaths, there is also statistically significant job creation by expansions. In the end, these results confirm that the nonexposed nontradable sector faces negative aggregate demand effects due to local exposure to the China shock, but is also the main reallocation destination of released workers from the exposed sector.

Panel B in Table 2 shows Chinese-induced predicted employment changes from columns 1-3 of Table 7. The formula we use to calculate the net employment change in sector $k$ from local exposure to China's PNTR status up to 2007 is

$$
\text { Predicted employment change in sector } k(P N T R)=\sum_{i} \hat{\beta}_{k}\left(G A P_{j}\right) P_{i 07} \text {, }
$$

where $\hat{\beta}_{k}$ is the net estimated coefficient, $G A P_{j}$ is the NTR gap for industry $j$, and $P_{i 07}$ is the working-age population in commuting zone $i$ in 2007. In contrast to the import-exposure results in Panel A, the PNTR-status results in panel B show that net job creation in the nonexposed nontradable sector (about 2.8 million jobs) is not sufficient to make up for the net job destruction in the exposed sector (about 3.9 million jobs). Accounting also for the significant net job destruction in the nonexposed tradable sector, local exposure to China's PNTR status causes a net overall loss of 1.8 million jobs.

The CBP net employment-to-population change coefficients in the last row of Table 7 are similar to the corresponding NETS coefficients in the first row, though the coefficient for the nonexposed nontradable sector is not significant. Table A.6 in the Appendix presents the PNTR estimation for the 1992-2011 period, and shows similar qualitative results to those in Table 7. The only relevant differences between them are that (i) in column 1 there is significant evidence of reductions in the rates of job creation by births and expansions for the exposed sector, with contractions becoming non-significant, and (ii) in column 3, the CBP net coefficient for the nonexposed nontradable sector is now significant, which gives us confidence in the job reallocation effects found with the NETS data. 


\section{Concluding Remarks}

The China shock is associated with net job destruction in the United States. Using job flows calculated from the universe of U.S. establishments, we showed that Chinese-induced net job destruction is mainly driven by deaths of establishments. This result holds for the two most influential measures of the China shock: the import penetration measure of Autor, Dorn, and Hanson (2013), and the PNTR-status measure of Pierce and Schott (2016). Moreover, our local labor markets analysis showed that our deaths results appears to be unique to the China shock; in particular, it does not emerge after a more general adverse U.S. labor demand shock. A novelty of this paper is that it provides evidence of job reallocation in local labor markets from the exposed sector to the nonexposed sector: workers released from the exposed sector (mainly due to deaths), are reabsorbed in the nonexposed nontradable sector mainly through births of establishments.

Our finding that the China shock is mostly felt through plant closings can improve our understanding of the costs associated with this trade. At the worker level, the long-run outcome may be better after a death than after a contraction (Stevens, 1997), in part because mass layoffs may reflect firms getting rid of lower-productivity workers first and thus giving a negative signal about the fired workers' quality (Gibbons and Katz, 1991). However, the better prospects after a plant closing than after a contraction are weaker if the closing plants hire more lower-productivity workers in the first place. Along these lines, Abowd, McKinney, and Vilhuber (2009) find that closings are more likely for firms that disproportionately hire workers from the bottom quartile of the human capital distribution.

Moreover, there is evidence of more adverse effects of plant closings on minorities and women. Black men experience larger earning losses than white men after plant closings (Hu and Taber, 2011), and more women report depression after plant closings than men (Brand, Levy, and Gallo, 2008). Hence, policy makers looking to tailor their response to adversely-affected groups may worry more about traditionally-disadvantaged groups after an establishment death than after a contraction.

From a local-labor-markets point of view, regional economies are likely to suffer more from deaths than from contractions (which tend to be one-off events or cyclical) because closed establishments can more permanently reduce local employment. Herzog and Schlottmann (1995) find, for example, that displaced workers have the lowest reemployment rates in areas that have suffered higher plant closing rates. Therefore, the persistent effects of establishments' deaths in local labor markets make a case for strengthening relocation incentives in the U.S. government's Trade Adjustment Assistance (TAA) program. 
With deaths playing such a crucial role in Chinese-induced employment dynamics, it is important to learn more about the dying establishments' characteristics. Are they small or large? Are they young or mature? If they are young, are they dying too soon (before realizing their potential), or are they old and dying as part of a healthy process of creative destruction? Previous research by Bernard and Jensen (2002) shows that the kinds of plants most likely to die after exposure to import competition from low-income countries are low-wage, labor-intensive plants within exposed industries, and those owned by multi-plant, multinational firms (Bernard and Jensen, 2007). Relatedly, Magyari (2017) indicates that plant closures from the China shock are mostly among multinational firms that are redistributing jobs between their factories. Further answers to these types of questions would deepen our understanding of the costs and benefits of trade with China.

Finally, an important caveat is that our paper does not assess the overall consequences of trade on job flows, but is restricted to the analysis of trade with one country (albeit the largest U.S. trading partner). And the fact that we find some positive reallocation effects highlights the fact that trade has beneficial effects on some sectors and firms. There are likely larger net beneficial effects from trade with other countries for which exports are larger relative to imports. Thus, although our research is focused on U.S. trade with one country, policy should focus more on the overall effects of trade. Our evidence suggests that trade with China has led to some "rusted-out factories ... across the landscape of our nation." But this is not the whole story. 


\section{References}

Abowd, J. M., K. L. McKinney, and L. Vilhuber (2009): "The Link between Human Capital, Mass Layoffs, and Firm Deaths," in Producer Dynamics: New Evidence from Micro Data, pp. 447-472. University of Chicago Press.

Acemoglu, D., D. Autor, D. Dorn, G. H. Hanson, and B. Price (2016): "Import Competition and the Great US Employment Sag of the 2000s," Journal of Labor Economics, 34(S1), S141-S198.

Acemoglu, D., V. M. Carvalho, A. Ozdaglar, and A. Tahbaz-Salehi (2012): "The Network Origins of Aggregate Fluctuations," Econometrica, 80(5), 1977-2016.

Autor, D., D. Dorn, G. Hanson, and K. Majlesi (2016): "Importing Political Polarization? The Electoral Consequences of Rising Trade Exposure," Working Paper 22637, National Bureau of Economic Research.

Autor, D. H., D. Dorn, and G. H. Hanson (2013): "The China Syndrome: Local Labor Market Effects of Import Competition in the United States," American Economic Review, 103(6), 21212168.

Bernard, A. B., J. Eaton, J. B. Jensen, and S. Kortum (2003): "Plants and Productivity in International Trade," American Economic Review, 93(4), 1268-1290.

Bernard, A. B., And J. B. Jensen (2002): "The Deaths of Manufacturing Plants," Discussion paper, National Bureau of Economic Research.

(2007): "Firm Structure, Multinationals, and Manufacturing Plant Deaths," The Review of Economics and Statistics, 89(2), 193-204.

Bernard, A. B., S. J. Redding, and P. K. Schott (2007): "Comparative Advantage and Heterogeneous Firms," Review of Economic Studies, 74(1), 31-66.

Brand, J. E., B. R. Levy, and W. T. Gallo (2008): "Effects of Layoffs and Plant Closings on Subsequent Depression among Older Workers," Research on Aging, 30(6), 701-721.

Davis, S. J., J. C. Haltiwanger, and S. Schuh (1996): Job Creation and Destruction. The MIT Press, Cambridge, MA.

Feenstra, R. C., J. Romalis, and P. K. Schott (2002): "U.S. Imports, Exports, and Tariff Data, 1989-2001," NBER Working Papers 9387, National Bureau of Economic Research.

Gibbons, R., And L. Katz (1991): "Layoffs and Lemons," Journal of Labor Economics, 9(4), $351-380$.

Groizard, J. L., P. Ranjan, and A. Rodriguez-Lopez (2014): "Offshoring and Jobs: The Myriad Channels of Influence," European Economic Review, 72, 221-239.

Haltiwanger, J., R. S. Jarmin, and J. Miranda (2013): "Who Creates Jobs? Small versus Large versus Young," Review of Economics and Statistics, 95(2), 347-361.

Herzog, H. W., and A. M. Schlottmann (1995): "Worker Displacement and Job-Search: A Regional Analysis of Structural Impediments to Re-Employment," Journal of Regional Science, $35(4), 553-577$.

Hu, L., And C. TABer (2011): "Displacement, Asymmetric Information, and Heterogeneous Human Capital," Journal of Labor Economics, 29(1), 113-152. 
Klein, M. W., S. Schuh, and R. K. Triest (2003): "Job Creation, Job Destruction, and the Real Exchange Rate," Journal of International Economics, 59(2), 239-265.

Magyari, I. (2017): "Firm Reorganization, Chinese Imports, and US Manufacturing Employment," Columbia University.

Meer, J., And J. West (2016): "Effects of the Minimum Wage on Employment Dynamics," Journal of Human Resources, 51(2), 500-522.

Melitz, M. J. (2003): "The Impact of Trade on Intra-Industry Reallocations and Aggregate Industry Productivity," Econometrica, 71(6), 1695-1725.

Neumark, D., B. Wall, and J. Zhang (2011): "Do Small Businesses Create More Jobs? New Evidence for the United States from the National Establishment Time Series," Review of Economics and Statistics, 93(1), 16-29.

Neumark, D., J. Zhang, and B. Wall (2007): "Employment Dynamics and Business Relocation: New Evidence from the National Establishment Time Series," Research in Labor Economics, $26,39-83$.

Pierce, J. R., And P. K. Schott (2012a): "Concording U.S. Harmonized System Codes over Time," Journal of Official Statistics, 28(1), 53-68.

Pierce, J. R., And P. K. Schott (2012b): "The Surprisingly Swift Decline of U.S. Manufacturing Employment," Working Paper 18655, National Bureau of Economic Research.

Pierce, J. R., And P. K. Schott (2016): "The Surprisingly Swift Decline of US Manufacturing Employment," American Economic Review, 106(7), 1632-1662.

Stevens, A. H. (1997): "Persistent Effects of Job Displacement: The Importance of Multiple Job Losses," Journal of Labor Economics, 15(1, Part 1), 165-188. 


\section{U.S. Job Flows and the China Shock}

\section{Appendix — For Online Publication}

Brian Asquith, Sanjana Goswami, David Neumark, and Antonio Rodriguez-Lopez

November 2017

\section{A Supporting Figures and Tables}

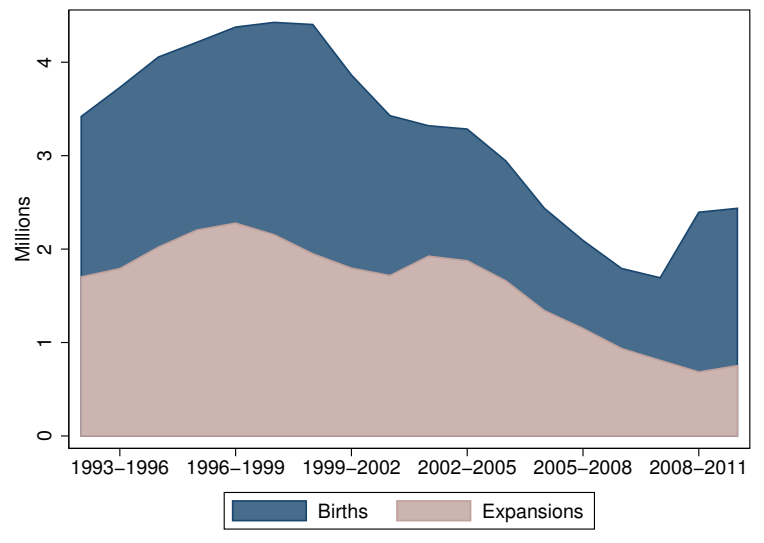

(a) Job creation decomposition

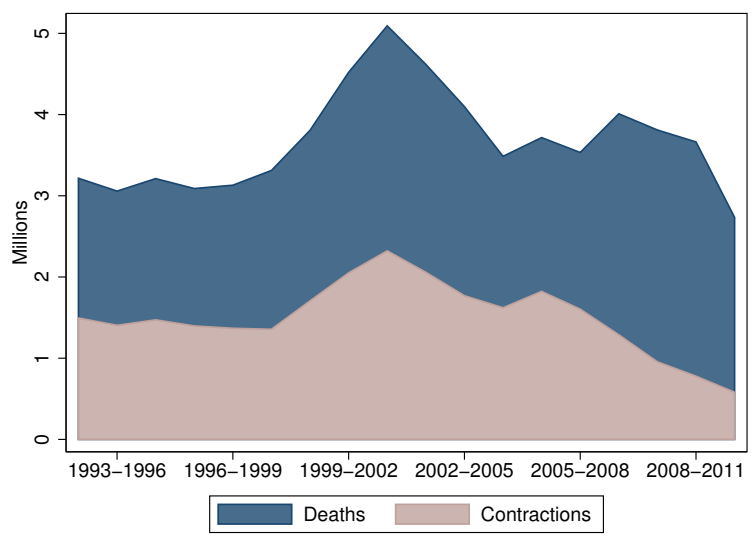

(c) Job destruction decomposition

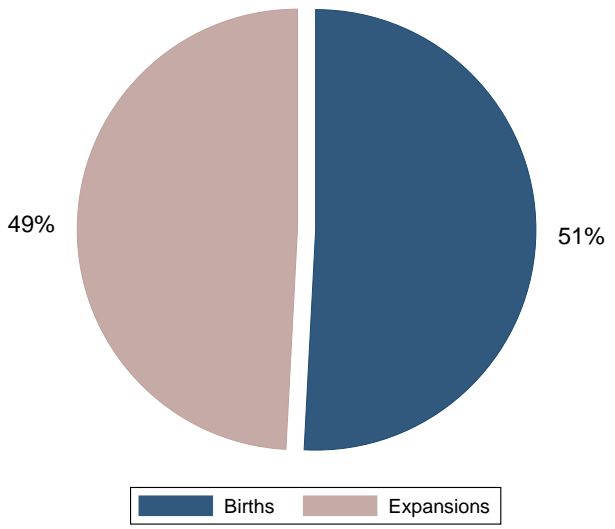

(b) Job creation shares (average)

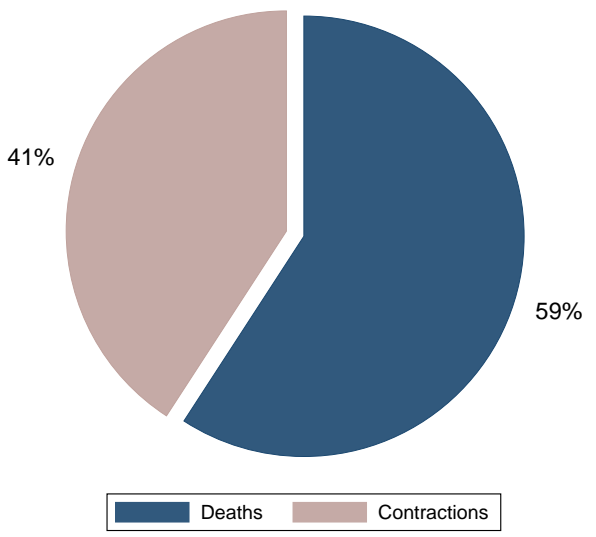

(d) Job destruction shares (average)

Figure A.1: Employment creation and destruction in the manufacturing industry (three-year windows) 


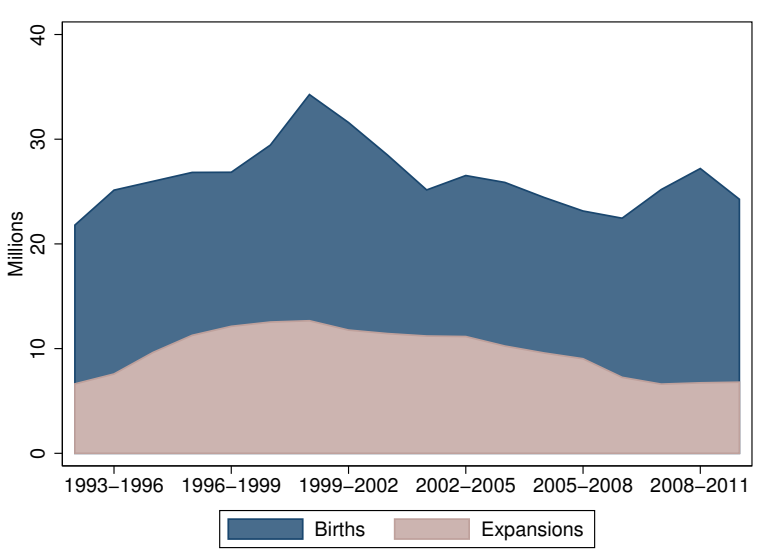

(a) Job creation decomposition

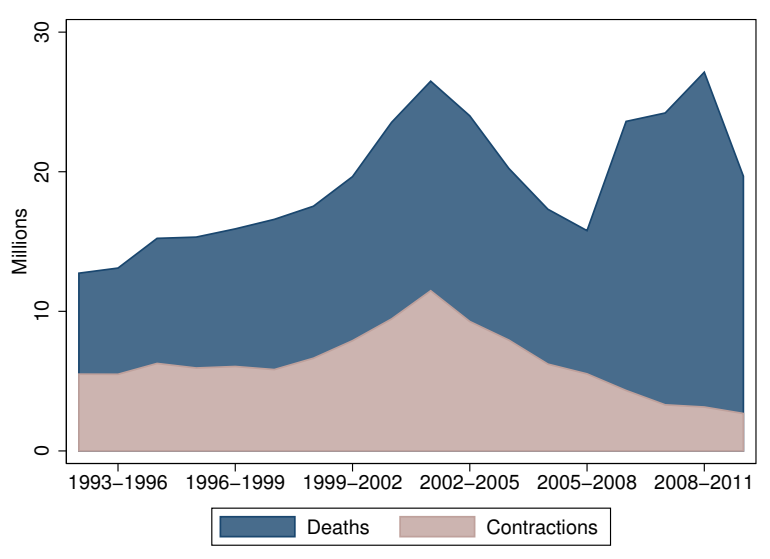

(c) Job destruction decomposition

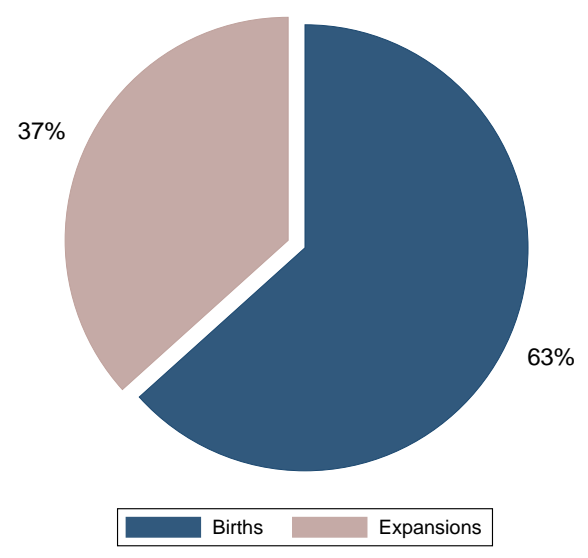

(b) Job creation shares (average)

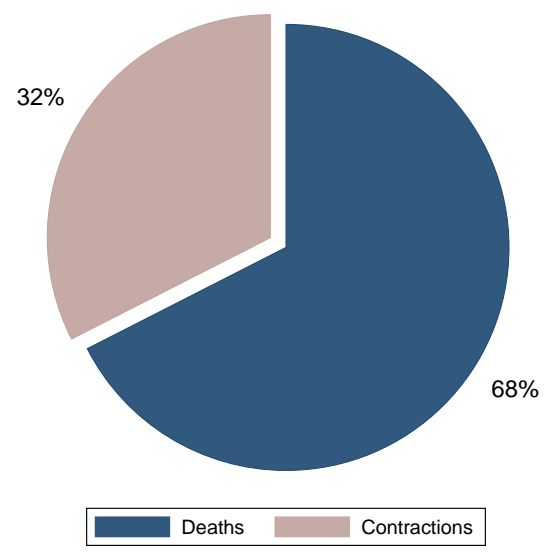

(d) Job destruction shares (average)

Figure A.2: Employment creation and destruction in the non-manufacturing industry (three-year windows) 
Table A.1: Job Flows Decomposition in All Industries (in Thousands)

\begin{tabular}{|c|c|c|c|c|c|c|c|c|c|}
\hline & 1992-95 & 1993-96 & 1994-97 & 1995-98 & 1996-99 & 1997-00 & 1998-01 & 1999-02 & 2000-03 \\
\hline Employment at initial year & 102,582 & 104,221 & 109,936 & 111,852 & 116,928 & 121,534 & 124,489 & 129,111 & 135,499 \\
\hline Employment at final year & 111,852 & 116,928 & 121,534 & 124,489 & 129,111 & 135,499 & 141,823 & 140,400 & 138,779 \\
\hline \multicolumn{10}{|l|}{ Change in employment } \\
\hline Due to births & 16,887 & 19,498 & 18,377 & 17,571 & 16,814 & 19,176 & 24,060 & 21,893 & 18,758 \\
\hline Due to deaths & $-8,953$ & $-9,261$ & $-10,699$ & $-11,067$ & $-11,618$ & $-12,716$ & $-12,989$ & $-14,223$ & $-16,854$ \\
\hline Due to expansions & 8,331 & 9,366 & 11,658 & 13,472 & 14,404 & 14,688 & 14,610 & 13,565 & 13,151 \\
\hline Due to contractions & $-6,995$ & $-6,896$ & $-7,739$ & $-7,338$ & $-7,417$ & $-7,184$ & $-8,347$ & $-9,946$ & $-11,775$ \\
\hline \multicolumn{10}{|l|}{ Net changes } \\
\hline Net extensive margin & 7,933 & 10,237 & 7,678 & 6,504 & 5,196 & 6,460 & 11,071 & 7,670 & 1,904 \\
\hline Net intensive margin & 1,336 & 2,471 & 3,919 & 6,134 & 6,987 & 7,505 & 6,263 & 3,620 & 1,376 \\
\hline \multirow[t]{2}{*}{ Net employment change } & 9,270 & 12,708 & 11,598 & 12,638 & 12,183 & 13,965 & 17,334 & 11,289 & 3,280 \\
\hline & 2001-04 & $2002-05$ & 2003-06 & 2004-07 & 2005-08 & 2006-09 & 2007-10 & 2008-11 & 2009-12 \\
\hline Employment at initial year & 141,823 & 140,400 & 138,779 & 139,196 & 142,114 & 143,874 & 145,047 & 148,038 & 140,508 \\
\hline Employment at final year & 139,196 & 142,114 & 143,874 & 145,047 & 148,038 & 140,508 & 143,912 & 146,838 & 144,794 \\
\hline \multicolumn{10}{|l|}{ Change in employment } \\
\hline Due to births & 15,350 & 16,789 & 16,909 & 15,952 & 15,053 & 16,058 & 19,464 & 22,178 & 19,159 \\
\hline Due to deaths & $-17,571$ & $-17,061$ & $-14,161$ & $-12,987$ & $-12,189$ & $-21,996$ & $-23,762$ & $-26,870$ & $-19,155$ \\
\hline Due to expansions & 13,126 & 13,028 & 11,906 & 10,925 & 10,183 & 8,190 & 7,418 & 7,416 & 7,544 \\
\hline Due to contractions & $-13,532$ & $-11,041$ & $-9,559$ & $-8,040$ & $-7,124$ & $-5,618$ & $-4,256$ & $-3,924$ & $-3,262$ \\
\hline \multicolumn{10}{|l|}{ Net changes } \\
\hline Net extensive margin & $-2,221$ & -273 & 2,748 & 2,966 & 2,864 & $-5,938$ & $-4,298$ & $-4,691$ & 3 \\
\hline Net intensive margin & -406 & 1,986 & 2,347 & 2,885 & 3,060 & 2,572 & 3,162 & 3,492 & 4,282 \\
\hline Net employment change & $-2,627$ & 1,713 & 5,095 & 5,851 & 5,924 & $-3,365$ & $-1,135$ & $-1,199$ & 4,285 \\
\hline
\end{tabular}

Notes: This table reports employment levels and three-year job flows for the overall U.S. economy. It uses NETS data from the universe of U.S

establishments with two or more employees in at least one year during the 1992-2012 period. 
Table A.2: Predicted U.S. Net Employment Changes due to the China Shock with NETS Data and CBP Data (in Thousands)

\begin{tabular}{|c|c|c|c|c|c|}
\hline \multirow[b]{2}{*}{ Specification } & \multirow[b]{2}{*}{ Exposure type-Sector } & \multicolumn{2}{|c|}{ Import exposure } & \multicolumn{2}{|c|}{ PNTR status } \\
\hline & & NETS & $C B P$ & NETS & $C B P$ \\
\hline \multicolumn{6}{|l|}{ 1992-2007: } \\
\hline Table 1, cols. 2 and 6 & Direct-Manufacturing & -477 & -862 & $-1,496$ & $-4,165$ \\
\hline Tables 4 and 5, col. 2 & Combined I-Total & -759 & $-1,567$ & $-2,484$ & $-7,495$ \\
\hline Tables 4 and 5 , col. 5 & Combined II-Total & -888 & $-1,918$ & $-2,825$ & $-10,200$ \\
\hline Tables 6 and 7 , col. 1 & Local-Exposed & $-2,128$ & $-2,078$ & $-3,896$ & $-3,153$ \\
\hline Tables 6 and 7 , col. 2 & Nonexposed tradable & 198 & -169 & -662 & $-1,103$ \\
\hline Tables 6 and 7 , col. 3 & Nonexposed nontradable & 2,225 & 2,331 & 2,792 & 1,955 \\
\hline \multicolumn{6}{|l|}{ 1992-2011: } \\
\hline 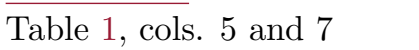 & Direct-Manufacturing & -491 & -789 & $-1,707$ & $-4,819$ \\
\hline Tables 4 and 5, col. 3 & Combined I-Total & -880 & $-1,549$ & $-3,693$ & $-8,345$ \\
\hline Tables 4 and 5, col. 6 & Combined II-Total & -999 & $-2,009$ & $-5,261$ & $-13,200$ \\
\hline Tables A.5 and A.6, col. 1 & Local-Exposed & $-2,515$ & $-2,758$ & $-6,620$ & $-5,282$ \\
\hline Tables A.5 and A.6, col. 2 & Nonexposed tradable & 114 & -216 & $-1,269$ & $-1,736$ \\
\hline Tables A.5 and A.6, col. 3 & Nonexposed nontradable & 2,222 & 2,684 & 4,693 & 4,145 \\
\hline
\end{tabular}

Notes: For the specifications described in the first column, and using either Chinese import exposure or China's PNTR status as the China-shock variable, this table compares predicted net employment changes with NETS data vs. predicted net employment changes with CBP data. Negative values indicate that the China-shock variable reduces employment. Equations (6) and (7) show general formulas to calculate predicted employment changes from Tables 1, 4, and 5, and equations (16) and (17) show the general formulas to calculate predicted employment changes from Tables 6, 7, A.5, and A.6. The numbers in bold denote predicted changes corresponding to statistically significant coefficients in the corresponding tables. 
Table A.3: IV Estimation of the Effects of Chinese Import Exposure on U.S. Employment — with Higher-Order Upstream and Downstream Linkages Across Industries

\begin{tabular}{|c|c|c|c|c|c|c|}
\hline & \multicolumn{3}{|c|}{$\begin{array}{c}\text { Combined measure I } \\
(\text { direct }+ \text { upstream })\end{array}$} & \multicolumn{3}{|c|}{$\begin{array}{c}\text { Combined measure II } \\
(\text { direct+upstream +downstream) }\end{array}$} \\
\hline & $(1)$ & $(2)$ & $(3)$ & $(4)$ & $(5)$ & $(6)$ \\
\hline Net employment growth & $\begin{array}{c}-0.35^{* *} \\
(0.15)\end{array}$ & $\begin{array}{c}-0.42^{* * *} \\
(0.15)\end{array}$ & $\begin{array}{c}-0.47^{* * *} \\
(0.16)\end{array}$ & $\begin{array}{c}-0.31^{* *} \\
(0.14)\end{array}$ & $\begin{array}{c}-0.36^{* * *} \\
(0.13)\end{array}$ & $\begin{array}{c}-0.38^{* * *} \\
(0.11)\end{array}$ \\
\hline \multicolumn{7}{|l|}{ Job flows } \\
\hline Births & $\begin{array}{c}0.07 \\
(0.09)\end{array}$ & $\begin{array}{c}0.07 \\
(0.07)\end{array}$ & $\begin{array}{c}0.04 \\
(0.09)\end{array}$ & $\begin{array}{c}0.09 \\
(0.08)\end{array}$ & $\begin{array}{c}0.09 \\
(0.06)\end{array}$ & $\begin{array}{c}0.06 \\
(0.07)\end{array}$ \\
\hline Deaths & $\begin{array}{c}0.33^{* * *} \\
(0.10)\end{array}$ & $\begin{array}{c}0.40^{* * *} \\
(0.10)\end{array}$ & $\begin{array}{c}0.47^{* * *} \\
(0.12)\end{array}$ & $\begin{array}{c}0.33^{* * * *} \\
(0.09)\end{array}$ & $\begin{array}{c}0.38^{* * *} \\
(0.09)\end{array}$ & $\begin{array}{c}0.42^{* * *} \\
(0.10)\end{array}$ \\
\hline Expansions & $\begin{array}{c}0.02 \\
(0.03)\end{array}$ & $\begin{array}{c}0.02 \\
(0.02)\end{array}$ & $\begin{array}{c}0.04 \\
(0.02)\end{array}$ & $\begin{array}{c}0.04 \\
(0.05)\end{array}$ & $\begin{array}{c}0.04 \\
(0.03)\end{array}$ & $\begin{array}{c}0.06 \\
(0.04)\end{array}$ \\
\hline Contractions & $\begin{array}{l}0.12^{* *} \\
(0.06)\end{array}$ & $\begin{array}{l}0.11^{*} \\
(0.06)\end{array}$ & $\begin{array}{l}0.08^{*} \\
(0.05)\end{array}$ & $\begin{array}{l}0.11^{* *} \\
(0.06)\end{array}$ & $\begin{array}{l}0.12^{* *} \\
(0.06)\end{array}$ & $\begin{array}{l}0.08^{* *} \\
(0.04)\end{array}$ \\
\hline Net extensive margin & $\begin{array}{c}-0.25^{* *} \\
(0.12)\end{array}$ & $\begin{array}{c}-0.33^{* * *} \\
(0.11)\end{array}$ & $\begin{array}{c}-0.43^{* * *} \\
(0.15)\end{array}$ & $\begin{array}{c}-0.24^{* * *} \\
(0.09)\end{array}$ & $\begin{array}{c}-0.29 * * * \\
(0.08)\end{array}$ & $\begin{array}{c}-0.36^{* * *} \\
(0.10)\end{array}$ \\
\hline Net intensive margin & $\begin{array}{l}-0.10 \\
(0.07)\end{array}$ & $\begin{array}{l}-0.09 \\
(0.08)\end{array}$ & $\begin{array}{l}-0.04 \\
(0.05)\end{array}$ & $\begin{array}{l}-0.07 \\
(0.08)\end{array}$ & $\begin{array}{l}-0.07 \\
(0.07)\end{array}$ & $\begin{array}{l}-0.02 \\
(0.05)\end{array}$ \\
\hline Job creation & $\begin{array}{c}0.09 \\
(0.10)\end{array}$ & $\begin{array}{c}0.10 \\
(0.07)\end{array}$ & $\begin{array}{c}0.08 \\
(0.09)\end{array}$ & $\begin{array}{c}0.13 \\
(0.10)\end{array}$ & $\begin{array}{l}0.13^{*} \\
(0.07)\end{array}$ & $\begin{array}{c}0.12 \\
(0.08)\end{array}$ \\
\hline Job destruction & $\begin{array}{c}0.44^{* * *} \\
(0.14)\end{array}$ & $\begin{array}{c}0.52^{* * *} \\
(0.14)\end{array}$ & $\begin{array}{c}0.55^{* * *} \\
(0.13)\end{array}$ & $\begin{array}{c}0.44^{* * *} \\
(0.13)\end{array}$ & $\begin{array}{c}0.50^{* * *} \\
(0.12)\end{array}$ & $\begin{array}{c}0.50^{* * *} \\
(0.10)\end{array}$ \\
\hline \multicolumn{7}{|l|}{ CBP data: } \\
\hline Net employment growth & $\begin{array}{c}-0.94^{* * *} \\
(0.25)\end{array}$ & $\begin{array}{c}-1.31^{* * *} \\
(0.35)\end{array}$ & $\begin{array}{c}-1.34^{* * *} \\
(0.39)\end{array}$ & $\begin{array}{c}-0.85^{* * *} \\
(0.22)\end{array}$ & $\begin{array}{c}-1.14^{* * *} \\
(0.30)\end{array}$ & $\begin{array}{c}-1.21^{* * *} \\
(0.36)\end{array}$ \\
\hline Sector $\times$ period controls & Yes & Yes & Yes & Yes & Yes & Yes \\
\hline Manf. sector controls & Yes & No & No & Yes & No & No \\
\hline Include 2008-2011 & No & No & Yes & No & No & Yes \\
\hline Observations & 958 & 958 & 958 & 958 & 958 & 958 \\
\hline
\end{tabular}

Notes: This table reports results for the effects of direct + upstream, and direct + upstream + downstream higher-order Chinese import exposure on annualized log-employment changes and job flows. All regressions include 479 industries, two subperiods (1992-1999 and either 1999-2007 or 1999-2011), and are weighted by 1992 employment. The net growth regression with CBP data is weighted by 1992 CBP employment, and is reported for the purpose of comparison with the net growth regression with NETS data. Standard errors (in parentheses) are clustered at the three-digit industry level. The coefficients are statistically significant at the $* 10 \%, * * 5 \%$, or $* * * 1 \%$ level. 
Table A.4: OLS Estimation of the Effects of China's PNTR Status on U.S. Employment — with Higher-Order Upstream and Downstream Linkages Across Industries

\begin{tabular}{|c|c|c|c|c|c|c|}
\hline & \multicolumn{3}{|c|}{$\begin{array}{c}\text { Combined measure I } \\
(\text { direct }+ \text { upstream })\end{array}$} & \multicolumn{3}{|c|}{$\begin{array}{c}\text { Combined measure II } \\
(\text { direct+upstream +downstream) }\end{array}$} \\
\hline & $(1)$ & $(2)$ & $(3)$ & $(4)$ & $(5)$ & $(6)$ \\
\hline Net employment growth & $\begin{array}{l}-0.13 \\
(0.14)\end{array}$ & $\begin{array}{l}-0.20 \\
(0.12)\end{array}$ & $\begin{array}{c}-0.36^{* *} \\
(0.17)\end{array}$ & $\begin{array}{l}-0.07 \\
(0.12)\end{array}$ & $\begin{array}{l}-0.16 \\
(0.10)\end{array}$ & $\begin{array}{c}-0.35^{* *} \\
(0.14)\end{array}$ \\
\hline \multicolumn{7}{|l|}{ Job flows } \\
\hline Births & $\begin{array}{c}0.11 \\
(0.14)\end{array}$ & $\begin{array}{c}0.09 \\
(0.12)\end{array}$ & $\begin{array}{c}0.07 \\
(0.16)\end{array}$ & $\begin{array}{c}0.09 \\
(0.11)\end{array}$ & $\begin{array}{c}0.07 \\
(0.10)\end{array}$ & $\begin{array}{c}0.02 \\
(0.12)\end{array}$ \\
\hline Deaths & $\begin{array}{c}0.24^{* * *} \\
(0.05)\end{array}$ & $\begin{array}{c}0.28^{* * *} \\
(0.05)\end{array}$ & $\begin{array}{c}0.44^{* * * *} \\
(0.10)\end{array}$ & $\begin{array}{c}0.17^{* * *} \\
(0.06)\end{array}$ & $\begin{array}{c}0.22^{* * *} \\
(0.05)\end{array}$ & $\begin{array}{c}0.39^{* * *} \\
(0.09)\end{array}$ \\
\hline Expansions & $\begin{array}{c}0.02 \\
(0.03)\end{array}$ & $\begin{array}{c}0.01 \\
(0.03)\end{array}$ & $\begin{array}{c}0.02 \\
(0.03)\end{array}$ & $\begin{array}{c}0.02 \\
(0.04)\end{array}$ & $\begin{array}{c}0.01 \\
(0.03)\end{array}$ & $\begin{array}{c}0.02 \\
(0.03)\end{array}$ \\
\hline Contractions & $\begin{array}{c}0.02 \\
(0.04)\end{array}$ & $\begin{array}{c}0.02 \\
(0.03)\end{array}$ & $\begin{array}{c}0.01 \\
(0.03)\end{array}$ & $\begin{array}{c}0.01 \\
(0.04)\end{array}$ & $\begin{array}{c}0.02 \\
(0.03)\end{array}$ & $\begin{array}{l}-0.00 \\
(0.03)\end{array}$ \\
\hline Net extensive margin & $\begin{array}{l}-0.13 \\
(0.14)\end{array}$ & $\begin{array}{l}-0.19 \\
(0.12)\end{array}$ & $\begin{array}{c}-0.37^{* *} \\
(0.18)\end{array}$ & $\begin{array}{l}-0.08 \\
(0.11)\end{array}$ & $\begin{array}{l}-0.15 \\
(0.10)\end{array}$ & $\begin{array}{c}-0.38^{* * *} \\
(0.14)\end{array}$ \\
\hline Net intensive margin & $\begin{array}{l}-0.00 \\
(0.05)\end{array}$ & $\begin{array}{l}-0.01 \\
(0.04)\end{array}$ & $\begin{array}{c}0.01 \\
(0.04)\end{array}$ & $\begin{array}{c}0.01 \\
(0.05)\end{array}$ & $\begin{array}{l}-0.01 \\
(0.04)\end{array}$ & $\begin{array}{c}0.02 \\
(0.04)\end{array}$ \\
\hline Job creation & $\begin{array}{c}0.13 \\
(0.14)\end{array}$ & $\begin{array}{c}0.11 \\
(0.12)\end{array}$ & $\begin{array}{c}0.09 \\
(0.15)\end{array}$ & $\begin{array}{c}0.10 \\
(0.11)\end{array}$ & $\begin{array}{c}0.08 \\
(0.10)\end{array}$ & $\begin{array}{c}0.04 \\
(0.11)\end{array}$ \\
\hline Job destruction & $\begin{array}{c}0.26^{* * *} \\
(0.07)\end{array}$ & $\begin{array}{c}0.30^{* * *} \\
(0.06)\end{array}$ & $\begin{array}{c}0.45^{* * *} \\
(0.10)\end{array}$ & $\begin{array}{r}0.18^{* *} \\
(0.07)\end{array}$ & $\begin{array}{c}0.24^{* * *} \\
(0.06)\end{array}$ & $\begin{array}{c}0.39^{* * *} \\
(0.09)\end{array}$ \\
\hline \multicolumn{7}{|l|}{ CBP data: } \\
\hline Net employment growth & $\begin{array}{c}-0.52^{* * *} \\
(0.11)\end{array}$ & $\begin{array}{c}-0.70^{* * *} \\
(0.11)\end{array}$ & $\begin{array}{c}-0.90^{* * *} \\
(0.16)\end{array}$ & $\begin{array}{c}-0.43^{* * *} \\
(0.10)\end{array}$ & $\begin{array}{c}-0.66^{* * *} \\
(0.11)\end{array}$ & $\begin{array}{c}-0.97^{* * *} \\
(0.16)\end{array}$ \\
\hline Sector $\times$ period controls & Yes & Yes & Yes & Yes & Yes & Yes \\
\hline Manf. sector controls & Yes & No & No & Yes & No & No \\
\hline Include 2008-2011 & No & No & Yes & No & No & Yes \\
\hline Observations & 958 & 958 & 958 & 958 & 958 & 958 \\
\hline
\end{tabular}

Notes: This table reports results for the effects of direct + upstream, and direct + upstream + downstream higher-order exposure to China's PNTR status on annualized log-employment changes and job flows. All regressions include 479 industries, two subperiods (1992-1999 and either 1999-2007 or 1999-2011), and are weighted by 1992 employment. The net growth regression with CBP data is weighted by 1992 CBP employment, and is reported for the purpose of comparison with the net growth regression with NETS data. Standard errors (in parentheses) are clustered at the three-digit industry level. The coefficients are statistically significant at the $* 10 \%, * * 5 \%$, or $* * * 1 \%$ level. 
Table A.5: IV Estimation of the Effects of Chinese Import Exposure on U.S. Commuting Zones by Sectoral Employment (1992-2011)

\begin{tabular}{|c|c|c|c|c|c|c|}
\hline & \multicolumn{3}{|c|}{ Chinese Import Exposure } & \multicolumn{3}{|c|}{ Bartik Shock } \\
\hline & Exposed & $\begin{array}{l}\text { Nonexposed } \\
\text { tradable }\end{array}$ & $\begin{array}{l}\text { Nonexposed } \\
\text { nontradable }\end{array}$ & Exposed & $\begin{array}{c}\text { Nonexposed } \\
\text { tradable }\end{array}$ & $\begin{array}{l}\text { Nonexposed } \\
\text { nontradable }\end{array}$ \\
\hline$\Delta($ Employment/Population $)$ & $\begin{array}{c}-1.12^{* * *} \\
(0.22)\end{array}$ & $\begin{array}{c}0.05 \\
(0.09)\end{array}$ & $\begin{array}{l}0.99^{*} \\
(0.51)\end{array}$ & $\begin{array}{c}0.19^{* * * *} \\
(0.04)\end{array}$ & $\begin{array}{c}-0.04^{* *} \\
(0.02)\end{array}$ & $\begin{array}{c}0.73^{* * *} \\
(0.11)\end{array}$ \\
\hline \multicolumn{7}{|l|}{ Job flows } \\
\hline Births & $\begin{array}{c}0.19 \\
(0.12)\end{array}$ & $\begin{array}{c}-0.13^{*} \\
(0.07)\end{array}$ & $\begin{array}{c}1.89^{* * *} \\
(0.55)\end{array}$ & $\begin{array}{c}0.22^{* * *} \\
(0.03)\end{array}$ & $\begin{array}{c}0.03^{* * *} \\
(0.01)\end{array}$ & $\begin{array}{c}1.36^{* * *} \\
(0.11)\end{array}$ \\
\hline Deaths & $\begin{array}{c}1.05^{* * *} \\
(0.18)\end{array}$ & $\begin{array}{l}-0.17^{*} \\
(0.09)\end{array}$ & $\begin{array}{l}1.16^{* *} \\
(0.51)\end{array}$ & $\begin{array}{c}0.17^{* * *} \\
(0.03)\end{array}$ & $\begin{array}{c}0.05^{* * *} \\
(0.01)\end{array}$ & $\begin{array}{c}0.84^{* * *} \\
(0.07)\end{array}$ \\
\hline Expansions & $\begin{array}{l}0.00 \\
(0.08)\end{array}$ & $\begin{array}{c}-0.14^{* *} \\
(0.06)\end{array}$ & $\begin{array}{l}0.46^{*} \\
(0.27)\end{array}$ & $\begin{array}{c}0.15^{* * *} \\
(0.02)\end{array}$ & $\begin{array}{l}0.02^{* *} \\
(0.01)\end{array}$ & $\begin{array}{c}0.37^{* * *} \\
(0.05)\end{array}$ \\
\hline Contractions & $\begin{array}{c}0.26^{* * *} \\
(0.06)\end{array}$ & $\begin{array}{l}-0.15^{*} \\
(0.08)\end{array}$ & $\begin{array}{c}0.21 \\
(0.18)\end{array}$ & $\begin{array}{c}0.01 \\
(0.01)\end{array}$ & $\begin{array}{c}0.03^{* * *} \\
(0.01)\end{array}$ & $\begin{array}{c}0.15^{* * *} \\
(0.04)\end{array}$ \\
\hline Net extensive margin & $\begin{array}{c}-0.86^{* * *} \\
(0.20)\end{array}$ & $\begin{array}{c}0.04 \\
(0.06)\end{array}$ & $\begin{array}{c}0.73 \\
(0.46)\end{array}$ & $\begin{array}{c}0.05^{* *} \\
(0.03)\end{array}$ & $\begin{array}{c}-0.02^{* *} \\
(0.01)\end{array}$ & $\begin{array}{c}0.52^{* * *} \\
(0.09)\end{array}$ \\
\hline Net intensive margin & $\begin{array}{c}-0.25^{* * * *} \\
(0.08)\end{array}$ & $\begin{array}{c}0.01 \\
(0.05)\end{array}$ & $\begin{array}{c}0.26 \\
(0.19)\end{array}$ & $\begin{array}{c}0.14^{* * *} \\
(0.02)\end{array}$ & $\begin{array}{l}-0.01 \\
(0.01)\end{array}$ & $\begin{array}{c}0.21^{* * * *} \\
(0.04)\end{array}$ \\
\hline Job creation & $\begin{array}{c}0.19 \\
(0.18)\end{array}$ & $\begin{array}{c}-0.27^{* *} \\
(0.12)\end{array}$ & $\begin{array}{c}2.35^{* * *} \\
(0.69)\end{array}$ & $\begin{array}{c}0.37^{* * *} \\
(0.05)\end{array}$ & $\begin{array}{c}0.05^{* * *} \\
(0.02)\end{array}$ & $\begin{array}{c}1.72^{* * *} \\
(0.14)\end{array}$ \\
\hline Job destruction & $\begin{array}{c}1.31^{* * *} \\
(0.18)\end{array}$ & $\begin{array}{c}-0.32^{* *} \\
(0.15)\end{array}$ & $\begin{array}{l}1.37^{* *} \\
(0.64)\end{array}$ & $\begin{array}{c}0.18^{* * *} \\
(0.03)\end{array}$ & $\begin{array}{c}0.09 * * * \\
(0.02)\end{array}$ & $\begin{array}{c}0.99 * * * \\
(0.10)\end{array}$ \\
\hline \multicolumn{7}{|l|}{ CBP data: } \\
\hline$\Delta$ (Employment/Population) & $\begin{array}{c}-1.42^{* * *} \\
(0.23)\end{array}$ & $\begin{array}{l}-0.11 \\
(0.11)\end{array}$ & $\begin{array}{l}1.38^{*} \\
(0.74)\end{array}$ & $\begin{array}{c}0.15^{* * *} \\
(0.02)\end{array}$ & $\begin{array}{c}0.02 \\
(0.01)\end{array}$ & $\begin{array}{c}0.52^{* * *} \\
(0.09)\end{array}$ \\
\hline
\end{tabular}

Notes: Using subperiods 1992-1999, 1999-2011, and import exposure as the China shock, this table reports $\hat{\beta}_{k}, \hat{\gamma}_{k}, \hat{\beta}_{k}^{F}$, and $\hat{\gamma}_{k}^{F}$, for $k \in\{1$ (exposed), 2(nonexposed tradable), 3(nonexposed nontradable)\}, from the estimation of specifications (14) and (15). All regressions include 4,332 observations (722 commuting zones, three sectors, and two subperiods) and the following controls: sectortime fixed effects, the commuting zone's manufacturing share (at the beginning of each period) interacted with sector dummies, and regional Census division dummies interacted with sector dummies. Regressions are weighted by 1992 commuting-zone population. The net regression with CBP data is reported for the purpose of comparison with the net regression with NETS data. Standard errors (in parentheses) are clustered at the commuting-zone level. The coefficients are statistically significant at the $* 10 \%, * * 5 \%$, or *** $1 \%$ level. 
Table A.6: OLS Estimation of the Effects of China's PNTR Status on U.S. Commuting Zones by Sectoral Employment (1992-2011)

\begin{tabular}{|c|c|c|c|c|c|c|}
\hline & \multicolumn{3}{|c|}{ PNTR Status } & \multicolumn{3}{|c|}{ Bartik Shock } \\
\hline & Exposed & $\begin{array}{c}\text { Nonexposed } \\
\text { tradable }\end{array}$ & $\begin{array}{l}\text { Nonexposed } \\
\text { nontradable }\end{array}$ & Exposed & $\begin{array}{c}\text { Nonexposed } \\
\text { tradable }\end{array}$ & $\begin{array}{l}\text { Nonexposed } \\
\text { nontradable }\end{array}$ \\
\hline$\Delta$ (Employment/Population) & $\begin{array}{c}-0.73^{* * *} \\
(0.08)\end{array}$ & $\begin{array}{c}-0.14^{* * *} \\
(0.05)\end{array}$ & $\begin{array}{c}0.52^{* *} \\
(0.21)\end{array}$ & $\begin{array}{c}0.14^{* * *} \\
(0.04)\end{array}$ & $\begin{array}{c}-0.04^{* *} \\
(0.02)\end{array}$ & $\begin{array}{c}0.77^{* * *} \\
(0.11)\end{array}$ \\
\hline \multicolumn{7}{|l|}{ Job flows } \\
\hline Births & $\begin{array}{c}-0.13^{* * *} \\
(0.04)\end{array}$ & $\begin{array}{l}-0.01 \\
(0.02)\end{array}$ & $\begin{array}{c}0.62^{* * *} \\
(0.16)\end{array}$ & $\begin{array}{c}0.21^{* * *} \\
(0.03)\end{array}$ & $\begin{array}{c}0.03^{* * *} \\
(0.01)\end{array}$ & $\begin{array}{c}1.40^{* * *} \\
(0.12)\end{array}$ \\
\hline Deaths & $\begin{array}{c}0.47^{* * *} \\
(0.06)\end{array}$ & $\begin{array}{c}0.10^{* * *} \\
(0.02)\end{array}$ & $\begin{array}{c}0.40^{* *} \\
(0.16)\end{array}$ & $\begin{array}{c}0.21^{* * *} \\
(0.03)\end{array}$ & $\begin{array}{c}0.06^{* * *} \\
(0.01)\end{array}$ & $\begin{array}{c}0.87^{* * *} \\
(0.08)\end{array}$ \\
\hline Expansions & $\begin{array}{c}-0.13^{* * *} \\
(0.03)\end{array}$ & $\begin{array}{l}-0.02 \\
(0.02)\end{array}$ & $\begin{array}{c}0.39^{* * * *} \\
(0.12)\end{array}$ & $\begin{array}{c}0.14^{* * *} \\
(0.02)\end{array}$ & $\begin{array}{l}0.02^{*} \\
(0.01)\end{array}$ & $\begin{array}{c}0.39 * * * \\
(0.05)\end{array}$ \\
\hline Contractions & $\begin{array}{l}-0.00 \\
(0.03)\end{array}$ & $\begin{array}{c}0.02 \\
(0.02)\end{array}$ & $\begin{array}{l}0.09^{*} \\
(0.05)\end{array}$ & $\begin{array}{c}0.01 \\
(0.01)\end{array}$ & $\begin{array}{c}0.03^{* * *} \\
(0.01)\end{array}$ & $\begin{array}{c}0.16^{* * *} \\
(0.05)\end{array}$ \\
\hline Net extensive margin & $\begin{array}{c}-0.60^{* * *} \\
(0.06)\end{array}$ & $\begin{array}{c}-0.11^{* * *} \\
(0.03)\end{array}$ & $\begin{array}{c}0.22 \\
(0.16)\end{array}$ & $\begin{array}{c}0.01 \\
(0.02)\end{array}$ & $\begin{array}{c}-0.03^{* * *} \\
(0.01)\end{array}$ & $\begin{array}{c}0.53^{* * *} \\
(0.09)\end{array}$ \\
\hline Net intensive margin & $\begin{array}{c}-0.13^{* * *} \\
(0.04)\end{array}$ & $\begin{array}{l}-0.03 \\
(0.03)\end{array}$ & $\begin{array}{c}0.29 * * \\
(0.11)\end{array}$ & $\begin{array}{c}0.13^{* * *} \\
(0.02)\end{array}$ & $\begin{array}{l}-0.01 \\
(0.02)\end{array}$ & $\begin{array}{c}0.23^{* * *} \\
(0.04)\end{array}$ \\
\hline Job creation & $\begin{array}{c}-0.25^{* * *} \\
(0.07)\end{array}$ & $\begin{array}{l}-0.02 \\
(0.03)\end{array}$ & $\begin{array}{c}1.01^{* * * *} \\
(0.22)\end{array}$ & $\begin{array}{c}0.36^{* * *} \\
(0.05)\end{array}$ & $\begin{array}{c}0.05^{* * *} \\
(0.02)\end{array}$ & $\begin{array}{c}1.80^{* * *} \\
(0.14)\end{array}$ \\
\hline Job destruction & $\begin{array}{c}0.47^{* * *} \\
(0.07)\end{array}$ & $\begin{array}{c}0.11^{* * * *} \\
(0.03)\end{array}$ & $\begin{array}{c}0.49^{* * * *} \\
(0.18)\end{array}$ & $\begin{array}{c}0.22^{* * *} \\
(0.04)\end{array}$ & $\begin{array}{c}0.09^{* * *} \\
(0.02)\end{array}$ & $\begin{array}{c}1.03^{* * *} \\
(0.11)\end{array}$ \\
\hline \multicolumn{7}{|l|}{ CBP data: } \\
\hline$\Delta$ (Employment/Population) & $\begin{array}{c}-0.56^{* * *} \\
(0.06)\end{array}$ & $\begin{array}{c}-0.18^{* * *} \\
(0.03)\end{array}$ & $\begin{array}{l}0.44^{*} \\
(0.26)\end{array}$ & $\begin{array}{c}0.15^{* * *} \\
(0.02)\end{array}$ & $\begin{array}{c}0.01 \\
(0.01)\end{array}$ & $\begin{array}{c}0.51^{* * *} \\
(0.09)\end{array}$ \\
\hline
\end{tabular}

Notes: Using subperiods 1992-1999, 1999-2011, and PNTR status as the China shock, this table reports $\hat{\beta}_{k}, \hat{\gamma}_{k}, \hat{\beta}_{k}^{F}$, and $\hat{\gamma}_{k}^{F}$, for $k \in\{1$ (exposed), 2(nonexposed tradable), 3(nonexposed nontradable)\}, from the estimation of specifications (14) and (15). All regressions include 4,332 observations (722 commuting zones, three sectors, and two subperiods) and the following controls: sectortime fixed effects, the commuting zone's manufacturing share (at the beginning of each period) interacted with sector dummies, and regional Census division dummies interacted with sector dummies. Regressions are weighted by 1992 commuting-zone population. The net regression with CBP data is reported for the purpose of comparison with the net regression with NETS data. Standard errors (in parentheses) are clustered at the commuting-zone level. The coefficients are statistically significant at the $* 10 \%,{ }^{*} 5 \%$, or $* * * 1 \%$ level. 